\title{
Interactive regulation of root exudation and rhizosphere denitrification by plant metabolite content and soil properties
}

\author{
Daniel Maurer (1) François Malique • Salah Alfarraj • Gada Albasher • \\ Marcus A. Horn · Klaus Butterbach-Bahl • Michael Dannenmann • \\ Heinz Rennenberg
}

Received: 22 January 2021 / Accepted: 26 June 2021 / Published online: 28 July 2021

(C) The Author(s) 2021

\begin{abstract}
Aims Root exudates are known to shape microbial activities in the rhizosphere and to be of fundamental importance for plant-soil-microbe-carbon-nitrogen interactions. However, it remains unclear how and to what extent the amount and composition of root exudation affects rhizosphere denitrification.

Methods In this study root exudation patterns and rhizosphere denitrification enzyme activity of three different grass species grown on two agricultural soils under two different soil water contents were investigated under controlled conditions.
\end{abstract}

Responsible Editor: Honghua He.

Supplementary Information The online version contains supplementary material available at https://doi. org/10.1007/s11104-021-05069-7.

D. Maurer $(\varangle) \cdot H$. Rennenberg

Chair of Tree Physiology, Institute of Forest Sciences,

University of Freiburg, Georges-Köhler-Allee 53/54,

79110 Freiburg, Germany

e-mail: daniel.maurer@posteo.de

F. Malique $\cdot$ K. Butterbach-Bahl · M. Dannenmann Institute for Meteorology and Climate Research,

Atmospheric Environmental Research (IMK-IFU),

Karlsruhe Institute of Technology (KIT),

82467 Garmisch-Partenkirchen, Germany

S. Alfarraj · G. Albasher · H. Rennenberg

College of Sciences, King Saud University, P.O. Box 2455,

Riyadh 11451, Saudi Arabia
Results We found that root exudation of primary metabolites largely depends on plant species, soil type, soil moisture and root exudation medium. In dependence of soil properties and soil moisture levels, plants largely controlled amount and quality of root exudation. Exudates affected denitrification activity and plant-microbe competition for nitrate. Specifically, exudation of organic acids stimulated denitrifying activity while the sugar lyxose exhibited an inhibitory effect.

Conclusion We show that interactive effects of physicochemical soil properties and species-specific effects of plant metabolism on root exudation act as a dominant control of rhizosphere denitrification, thereby explaining more than half of its variance.

\footnotetext{
M. A. Horn

Institute of Microbiology, Leibniz University Hannover, Herrenhäuser Str. 2, 30419 Hannover, Germany

H. Rennenberg

Center of Molecular Ecophysiology (CMEP), College of Resources and Environment, Southwest University, No. 2, Tiansheng Road, Beibei district, 400715 Chongqing, People's Republic of China
} 
Keywords Denitrification - Leaf and root metabolism $\cdot$ Plant-microbe interaction $\cdot$ Root exudation $\cdot$ Soil properties

\section{Introduction}

Plants constantly release a large variety of monomeric carbon (C) compounds into the rhizosphere via root exudation. It is estimated, that root exudates account for about 5-21\% of photosynthetically fixed C (Nguyen 2003; Derrien et al. 2004). Exudated compounds are usually referred to as primary metabolites, such as sugars, amino acids and organic acids and secondary metabolites, such as phenolic, flavonoids and terpenoids.

Roots can exudate metabolites either actively or passively across the plasma membrane at the root tip. Active transport against the concentration gradient is carried out by energy-dependent ABC (ATP-Binding Cassette) transporters (secondary metabolites) or ALMT (Aluminium-activated-malate transporters) and MATE (Multidrug and toxic compound extrusion) transporters (malate and citrate). Passive transport, which accounts for the largest amount of root exudation, is carried out through diffusion due to the concentration gradient between the soil solution and the cytoplasm. However, there are ways for plants to control passive transport, e.g. through modification of efflux carriers and channels or re-uptake of exudated compounds (Canarini et al. 2019).

Main functions of root exudation include (i) nutrient mobilization, (ii) removal of toxic compounds from roots, (iii) growth inhibition of competing plants, (iv) release of plant defence compounds, (v) attraction of beneficial microbial communities, (vi) detoxification of metals and (vii) balance of metabolite abundances in roots (Haichar, 2014; Maurer et al. 2018; Oburger and Jones 2018). Depending on the environment of plants, these functions have different effects on amount and composition of root exudates. Thereby, root exudation is not only altered by plant species, cultivar and plant age (M.S. Aulakh et al., 2001a,b; Dietz et al., 2019), but is also affected by soil biotic and abiotic factors, including nutrient availability, soil water content or microbial activity in the soil (Neumann and Römheld 2007; Vranova et al. 2013). Plant internal processes that may control root exudation of carbohydrates include photosynthesis and the allocation of its products to the roots, the consumption of products of photosynthesis in the root growth and development as well as the generation of energy by respiration for these processes (Maurer et al. 2018). For root exudation of amino compounds, also nitrate reduction - in the leaves of herbaceous plants and in roots of most temperate forest trees - and the exchange of amino compounds between shoots and roots will also contribute to the control of root exudation. In addition, storage processes of carbohydrate and reduced nitrogen by starch and storage protein synthesis, respectively, will counteract root exudation. However, the contribution of these mechanisms to the control of root exudation, as well as the significance of membrane transport processes for this control are largely unknown.

One of the most important factors for growth and development of plants are bioavailable nutrients in the soil. However, nutrients, such as N, P or $\mathrm{S}$ are mostly organically bound in natural ecosystems and, as a consequence, not directly available for plants (Jacoby et al. 2017). However, soil microbes are able to depolymerize and mineralize organically bound nutrients, which are consequently released to the rhizosphere and therefore become available for plants (Schimel and Bennett 2004; Richardson and Simpson 2011). Thus, a common plant-microbe feedback mechanism is the mobilization of nutrients by microorganisms and the provision of $\mathrm{C}$ compounds for heterotrophic microbial growth and processes by plants. However, plants also compete with microorganisms for the use of monomeric organic and mineral nutrients released and mineralized from organic polymers. In this context, root exudation also offers mechanisms for plants to control microbial competition through regulating $\mathrm{C}$ availability for heterotrophic microbial processes or through the release of inhibiting compounds (Chapman et al. 2006; Dannenmann et al. 2009). A key plant-microbe interaction is thought to be that with heterotrophic denitrifying microorganisms in the rhizosphere under anaerobic conditions. Denitrifiers primarily use nitrate $\left(\mathrm{NO}_{3}{ }^{-}\right)$, but also nitrite $\left(\mathrm{NO}_{2}^{-}\right)$, nitric oxide (NO) or nitrous oxide $\left(\mathrm{N}_{2} \mathrm{O}\right)$ as alternative electron acceptors to maintain respiration under anaerobic and semi-anaerobic conditions. The ecological importance of denitrification is immense as this process (i) both produces and/or consumes the potent greenhouse gas $\mathrm{N}_{2} \mathrm{O}$, 
(ii) closes the global nitrogen cycle by converting reactive $\mathrm{N}$ forms to inert dinitrogen gas $\left(\mathrm{N}_{2}\right)$; (iii) consumes nitrate, thereby competing with plants for nutrients and reducing plant nitrogen use efficiency in agriculture, and (iv) reduces nitrate contamination in agricultural and adjacent natural ecosystems. Organic substances used by denitrifiers for respiration originate either from organic soil constituents including plant residues or from root exudates of plants. While the main controlling factor of denitrifiers in the soil by plants is thought to be the release of $\mathrm{C}$ compounds, there are multiple others ways for plants to influence denitrifying bacteria in the soil, such as respiration of $\mathrm{O}_{2}$, consumption of water, (re-)uptake of rhizosphere compounds or even exudation of specific compounds which inhibit denitrifiers (Bardon et al. 2014, 2018; Rigby et al. 2016; Jacoby et al. 2017). In a recent study it was shown that the presence of plants on agricultural soil can stimulate the denitrification enzyme activity (DEA) in a species specific manner which can vary across different soil types (Malique et al. 2019). Furthermore, Graf et al. (2019) showed effects of plant control on denitrifying bacteria was shown by intercropping Lucerne (Medicago sativa) with cocksfoot (Dactylis glomerata), which altered $\mathrm{N}_{2} \mathrm{O}$-reducing communities and promoted $\mathrm{N}_{2} \mathrm{O}$ production compared to sole cropping of those species. Therefore, plants are believed to play a crucial role in the control of denitrification, but the quantitative importance of the individual underlying mechanism as well as of the total plant effects on soil denitrification remain unclear. For a better understanding of plant control on denitrification, it is in particular interesting to link controls, composition and amount of root exudates to the activity of denitrifying bacteria in the rhizosphere (Henry et al. 2008).

In recent years, research focused on controls and regulation of root exudation under changing environmental conditions. Thereby, most studies focused on stress factors, such as drought, nutrient deficiency or aerobic ions in the soil (Vives-Peris et al. 2019). General adaptations of root exudation by plants grown under different soil moisture levels or different soils, particularly combined with the activity of microbes in the rhizosphere thereby considering chemical species composition of root exudation have not been studied. However, changes in soil properties or oxygen availability in the soil also have large impact on the accessibility of nutrients or microbial activity in the soil.

In this study, we aimed to characterize (i) the influence of general soil properties, soil moisture and different plant species on the composition and amount of root exudation, (ii) the relationships of root exudates with plant internal metabolite composition of roots and shoots, (iii) the control of root exudation on rates of rhizosphere denitrifying enzyme activity and (iv) the potential role of amount and composition of root exudation in regulating competition for nitrate between denitrifiers and plants.

Therefore, three major crop/ grass species (ryegrass, barley, wheat) were grown under greenhouse conditions on two different agricultural soils at two different soil water contents. Root exudates were collected in two different incubation solutions. We analysed incubation solutions as well as metabolites of root and leaf material via gas chromatography-mass spectrometry (GC-MS) and plant ${ }^{15} \mathrm{NO}_{3}{ }^{-}$ uptake capacities via isotope-ratio mass spectrometry (IRMS). Results were compared with DEA (data from (Malique et al. 2019) in bulk and rhizosphere soils in a full factorial design. We hypothesized, that (i) plant species, soil moisture and soil type determine root exudation, (ii) root exudation controls DEA with stronger effects at higher soil water contents but lower soil $\mathrm{C}$ and $\mathrm{N}$ concentrations, (iii) The plant-species specific composition and quantity of root exudation regulates stimulating or inhibiting effects on DEA and (iv) in contrast to bidirectional effect of root exudation, plant $\mathrm{NO}_{3}{ }^{-}$-uptake is generally negatively correlated to DEA.

\section{Material and methods}

Soils, plant species and experimental set up

The present experiments were conducted under controlled conditions with wheat, barley and ryegrass as described by Malique et al. (2019). Plants were cultivated on two different agricultural soils, a Haplic Luvisol of silty loam texture from the arable land of an experimental field site at Rotthalmünster (latitude $\mathrm{N} 48^{\circ} 21^{\prime}$, longitude $\mathrm{E} 13^{\circ} 11^{\prime}$, elevation $360 \mathrm{~m}$ above sea level) and a Fluvic Gleysol of clay loam texture taken at the grassland research station of the 
University of Gießen (latitude N50 $32^{\prime}$, longitude E $8^{\circ} 41.3^{\prime}$, elevation $172 \mathrm{~m}$ above sea level). The soils were chosen as they represent two typical agricultural soils, which show differences in texture and organic matter. Thereby, we expected differences in plant-soil-microbe interactions between those two soils. The soils were homogenized, air dried and stored at $4{ }^{\circ} \mathrm{C}$ before use (see Malique et al. (2019) for details). Soil properties are listed in Table S1; subsequently, soils are referred to as Rotthalmünster and Gießen. Wheat (Tricitum aestivum, from Saatzucht Bardowick, article number 79916-d), barley (Hordeum vulgare, from Saatzucht Bardowick, article number 79739-e), and ryegrass (Lolium multiflorum, from samenshop24, article number 44064) were grown from seeds, washed once with $2 \% \mathrm{H}_{2} \mathrm{O}_{2}$, twice with water and pre-germinated on 1\% agar-agar (Merck KGaA, Darmstadt, Germany) for six days. Germinated seeds were planted in 1L (height: $12 \mathrm{~cm}$; diameter $11 \mathrm{~cm}$ ) plastic pots (3 plants per pot) filled either with soil originating from Gießen or Rotthalmünster. Soils were fertilized with $100 \mathrm{mg} \mathrm{N} \mathrm{kg}^{-1}$ dry soil (approx. $200 \mathrm{~kg} \mathrm{ha}^{-1}$ ) using standard NPK fertilizer $\left(8 \% \mathrm{~N}\left(2.3 \% \mathrm{NO}_{3}{ }^{-}-\mathrm{N}\right.\right.$, $3.7 \% \mathrm{NH}_{4}{ }^{+}-\mathrm{N}, 2 \%$ Urea-N), $8 \% \mathrm{P}, 6 \% \mathrm{~K}$; Wuxal ${ }^{\circledR}$, Hauert MANNA Düngerwerke $\mathrm{GmbH}$, Nürnberg, Germany), with the fertilizer being mixed homogeneously with the soil. Plants were exposed to artificial light (Habana IP23-680, $400 \mathrm{~W}$, from Lanzini Illuminazione) for $10 \mathrm{~h}$ per day (from $9 \mathrm{am}$ to $7 \mathrm{pm}$ ) at $150 \mu \mathrm{mol} \mathrm{m} \mathrm{m}^{-2} \mathrm{~s}^{-1}$. Soil moisture content was kept constant at (a) 50\% Water Filled Pore Space (WFPS) (Rotthalmünster and Gießen), (b) at 34\% (Rotthalmünster), or (c) 40\% WFPS (Gießen). The difference in the lower soil moisture contents for each soil correspond to the lowest moisture content at which plant growth was not visibly affected.

Measurements were conducted after plant cultivation in the different soils at 50\% WFPS and $34 / 40 \%$ WFPS for 30 days. From each pot two similar sized plants were used for root exudation sampling in two different incubation solutions (see below). Thus, the experiment (Table S2) included two soils (Rotthalmünster and Gießen), three plant species (wheat, barley and ryegrass), two soil moisture levels and two different root exudation sampling solutions. Each combination (plant, soil, soil moisture, incubation) was replicated five times.
Root exudate sampling

After plants have been grown for 30 days, the rhizosphere and bulk soils were sampled for analysis of denitrification enzyme activity (analysed by Malique et al. 2019, see for details of DEA analysis), and parallel root exudation analysis. For the latter, the root system was carefully washed with de-ionized water and soil particles were completely removed. Two different incubation solutions were used for root exudate collection with each one intact plants: sterile distilled water (Wa-treatment) and a modified Hoagland solution (produced with sterile distilled water; Ho-treatment) containing ${ }^{15} \mathrm{~N}$-Nitrate. The Hoagland solution contained 1,25 mM K ${ }^{15} \mathrm{NO}_{3}, 1,25 \mathrm{mM} \mathrm{CaCl}_{2} \bullet 2 \mathrm{H}_{2} \mathrm{O}$, $0,25 \mathrm{mM} \mathrm{NH}_{4} \mathrm{Cl}, 0,25 \mathrm{mM} \mathrm{MgSO}{ }_{4} \bullet 7 \mathrm{H}_{2} \mathrm{O}, 20 \mu \mathrm{M}$ Fe EDTA, 11,25 $\mu \mathrm{M} \mathrm{H}_{3} \mathrm{BO}_{3}, 2,5 \mu \mathrm{M} \mathrm{MnCl}_{2} \bullet 4 \mathrm{H}_{2} \mathrm{O}$, $0,19 \mu \mathrm{M} \quad \mathrm{ZnSO}_{4} \bullet 7 \mathrm{H}_{2} \mathrm{O}, 0,06 \mu \mathrm{M} \quad \mathrm{CuSO}_{4} \bullet 5 \mathrm{H}_{2} \mathrm{O}$, $0,13 \mu \mathrm{M} \mathrm{Na}_{2} \mathrm{MoO}_{4} \bullet 2 \mathrm{H}_{2} \mathrm{O}$ and $2,5 \mathrm{mM} \mathrm{KH}_{2} \mathrm{PO}_{4}$ (Rotthalmünster) or $0,25 \mathrm{mM} \mathrm{KH_{2 }} \mathrm{PO}_{4}$ (Gießen). Microbial activity was largely suppressed in both incubation solutions by addition of ampicillin $\left(10 \mathrm{mg} \mathrm{L}^{-1}\right)$. Previous studies reported that incubation of roots for $2 \mathrm{~h}$ in de-ionized water is a useful method to collect root exudates without harming the root system (Aulakh et al. 2001a; Neumann and Römheld 2007; Valentinuzzi et al. 2015). Therefore, roots were placed for $2 \mathrm{~h}$ in $50 \mathrm{~mL}$ falcon tubes (Corning, New York, USA) containing approximately $20 \mathrm{~mL}$ of modified Hoagland solution or sterile distilled water. The incubation experiments took place under the same controlled condition as described for plant growth between $11 \mathrm{am}$ and $3 \mathrm{pm}$ to avoid disturbance by diurnal changes. The root incubation solutions of plants grown under 30/40\% WFPS were permanently gassed with synthetic air (Alphagaz 1, Air Liquide, 20,5\% $\mathrm{O}_{2}$ in $\mathrm{N}_{2}$ ) in the falcon tubes to achieve aerobic conditions; the root incubation solutions of plants grown under 50\% WFPS were gassed with $\mathrm{N}_{2}$ (Alphagaz 2, Air Liquide, purity $>99.9999 \%$ ) to achieve anaerobic conditions. These condition in the incubation solutions were applied to mimic aerobic and anaerobic microsites in the soil.

After $2 \mathrm{~h}$ incubation, roots and shoots were separated with scissors, dried with paper tissue and weighted. Roots and shoots of the Wa-treatment were immediately frozen and stored at $-80{ }^{\circ} \mathrm{C}$ until gas chromatography-mass spectrometry (GC-MS) analyses; roots and shoots of the Ho-treatment were dried 
for two days in the drying oven, weighted and subsequently prepared for isotope-ratio mass spectrometry (IRMS). The incubation solutions of both treatments were immediately frozen and stored at $-80{ }^{\circ} \mathrm{C}$ until GC-MS analyses.

\section{Metabolome analyses by GC-MS}

Metabolites of roots and shoots were extracted and derivatized using a modification of the method described by Kreuzwieser et al. (2009). Approximately $50 \mathrm{mg}$ of homogenized frozen plant material was suspended with $300 \mu \mathrm{L}$ Methanol (100\%). Thereafter, $30 \mu \mathrm{L}$ Ribitol $\left(2 \mathrm{mg} \mathrm{mL}^{-1}\right)$ was added as internal standard, samples were incubated at $70{ }^{\circ} \mathrm{C}$ for 15 min and shaken at 1,400 r.p.m. $200 \mu$ L Chloroform was added and samples were incubated for $5 \mathrm{~min}$ at $37^{\circ} \mathrm{C}$ and 1,400 r.p.m. and, subsequently, centrifuged for $5 \mathrm{~min}$ and $15,000 \mathrm{~g}$. An aliquot of $80 \mu \mathrm{L}$ of the supernatant was lyophilised overnight. For derivatization, $20 \mu \mathrm{L}$ of a $20 \mathrm{mg} \mathrm{ml}^{-1}$ solution of methoxyamine hydrochloride in anhydrous pyridine (SigmaAldrich Inc., Steinheim, Germany) was added to the dried extracts. Samples were incubated for $90 \mathrm{~min}$ at $30{ }^{\circ} \mathrm{C}$ and $1,400 \mathrm{~g}$ before $35 \mu \mathrm{L}$ of N-methyl-N(trimethylsilyl)-trifluoroacetamide (MSTFA; SigmaAldrich) was added and samples were derivatized at $37^{\circ} \mathrm{C}$ for $30 \mathrm{~min}$ and with shaking at $1,400 \mathrm{rpm}$.

Frozen incubation solutions of root exudates were lyophilized for approximately five days. For derivatization, $500 \mu \mathrm{L}$ of a $20 \mathrm{mg} \mathrm{ml}^{-1}$ solution of methoxyamine hydrochloride in anhydrous pyridine was added to the dried extracts. Solutions were vortexed and shortly centrifuged before $20 \mu \mathrm{L}$ aliquots were derivatized as explained above.

Derivatized samples of root and shoot extracts and root exudates were analysed with a GC-MS system (Agilent GC $6890 \mathrm{~N}$ coupled to a 5975C quadrupole MS detector; Agilent Technologies, Palo Alto, CA, USA), equipped with an autosampler (MultiPurpose Sampler MPS2; Gerstel, Mülheim, Germany) and controlled by the Agilent MASSHUNTER software (Agilent Technologies). For this purpose, $1 \mu \mathrm{L}$ aliquots were injected in splitless mode into the system and metabolites were separated on a capillary column (HP-5 ms ultra inert, $0.25 \mathrm{~mm}$ ID, $0.25 \mathrm{~lm}$ film thick- ness, 30 m length; Agilent Technologies). Run conditions as well as MS settings were as described by Kreuzwieser et al. (2009). For peak identification and detection of compounds, the Golm Metabolome Database was used in combination with the Quantitative Analyses software (Agilent Technologies). Additionally, standards were used for peak identification and quantification of samples (Table S3). We quantified 34 compounds, which showed high abundances and well correlations (Table S6-S8 and S10) in roots, shoots as well as in root exudates. Peak areas of plant material were normalized using the peak area of Ribitol and the fresh weight of samples; peak areas of root exudates were normalized with the dry weight of the roots and the incubation volume applied. Common contaminations and artefact peaks were identified by blanks and were subtracted from sample peaks.

${ }^{15} \mathrm{~N}$-uptake experiment and IRMS analysis

Aliquots of 1-2 mg oven dried, pulverized plant tissue of roots and shoots were weighed into tin capsules for the analyses of total $\mathrm{N}$ contents and ${ }^{15} \mathrm{~N}$ abundance. For this purpose, samples were combusted in an element analyser (Flash EA 1112 HT, Thermo Fisher Scientific, Bremen, Germany) coupled to an isotope ratio mass spectrometer (Delta XP, Thermo Fisher Scientific). ${ }^{15} \mathrm{~N}$-uptake capacities were calculated from the ${ }^{15} \mathrm{~N}$ signature of nitrate in the root incubation solution, the ${ }^{15} \mathrm{~N}$ accumulation in roots and shoots over natural abundance, the incubation time, and the root dry mass as previously reported by Fasbender et al. (2017).

\section{Statistical analyses}

One-way ANOVAs $(\mathrm{P}=0.05, \mathrm{a}=0.95$, Fisher's LSD post-hoc test) were used to determine significant differences of ${ }^{15} \mathrm{NO}_{3}{ }^{-}$-uptake capacities and total $\mathrm{C}$ and $\mathrm{N}$ contents of root exudates. Normal distribution of the data was tested using the Kolmogorov-Smirnov test and the homogeneity of variances was tested with the Levene ${ }^{2}$ test (both $\mathrm{P}=0.05$ ). Kruskal-Wallis ANOVA ( $\mathrm{P}=0.05$, Mann-Whitney U post-hoc test) were used to determine differences in concentrations of amino acids, carbohydrates and organic acids. Correlation analysis were conducted with plants incubated in Hoagland solution and the Pearson correlation coefficient was applied. Only significant correlations $(P<0.05)$ were selected. We used multiple linear regression to interpret different drivers of DEA (data from Malique et al. 2019). The model was built 
with quantified exudated compounds (Table S3) and $\mathrm{NO}_{3}{ }^{-}$-uptake capacities. Only significant correlations were selected and compounds with strong multicollinearity were excluded. For visualization of differences between root exudates, fold-changes values $\left(\log _{2}\right)$ were calculated and statistical differences were indicated by the Welch's unequal variances t-test. The software ORIGIN PRO 2019 (OriginLab Corp., Northampton, MA, USA) was used for statistical analyses. For heatmaps, 20 compounds were selected which include the 10 most abundant compounds of each treatment (Table S2) and plant species. Data of quantified samples were uploaded to the online platform MetaboAnalyst (Chong et al. 2019), were $\log _{10}$ normalized, and heatmaps (distance measure:
Euclidean; clustering algorithm: Ward) were plotted. The sample size of each treatment was four or five and is specified in Table S2.

\section{Results}

Plant species, soil moisture and soil type determine root exudation

Total $\mathrm{C}$ and $\mathrm{N}$ of root exudates varied largely between plant species, soil water content, soil type and root incubation solution (Table 1). Total $\mathrm{C}$ exudation ranged between 0.15 and $1.64 \mathrm{mmol} \mathrm{L}^{-1} \mathrm{~h}^{-1} \mathrm{~g}^{-1}$ root DW and was about 100 -fold higher than total $\mathrm{N}$

Table 1 Total $\mathrm{C}$ and $\mathrm{N}$ exudation in all conducted treatments

\begin{tabular}{|c|c|c|c|c|c|c|c|c|}
\hline & \multicolumn{4}{|c|}{ Distilled water } & \multicolumn{4}{|c|}{ Modified Hoagland solution } \\
\hline & \multicolumn{2}{|c|}{ Rotthalmünster } & \multicolumn{2}{|l|}{ Gießen } & \multicolumn{2}{|l|}{ Rotthalmünster } & \multicolumn{2}{|l|}{ Gießen } \\
\hline & $34 \%$ WFPS & $50 \%$ WFPS & $40 \%$ WFPS & $50 \%$ WFPS & $34 \%$ WFPS & $50 \%$ WFPS & $40 \%$ WFPS & $50 \%$ WFPS \\
\hline \multicolumn{9}{|l|}{ Ryegrass } \\
\hline $\begin{array}{l}\mathrm{C}[\mathrm{mmol} \\
\left.\mathrm{L}^{-1} \mathrm{~h}^{-1} \mathrm{~g}^{-1}\right]\end{array}$ & $0.24 \pm 0.07^{\mathrm{A}}$ & $0.49 \pm 0.23^{\mathrm{A}}$ & $1.55 \pm 0.79^{\mathrm{B}}$ & $0.5 \pm 0.12^{\mathrm{A}}$ & $1.24 \pm 0.31^{\mathrm{B}}$ & $0.33 \pm 0.1^{\mathrm{A}}$ & $0.99 \pm 0.28^{\mathrm{B}}$ & $0.32 \pm 0.08^{\mathrm{A}}$ \\
\hline $\begin{array}{l}\mathrm{N}[\mu \mathrm{mol} \\
\left.\quad \mathrm{L}^{-1} \mathrm{~h}^{-1} \mathrm{~g}^{-1}\right]\end{array}$ & $4.5 \pm 1.2^{\mathrm{A}}$ & $7.7 \pm 6.9^{\mathrm{ABC}}$ & $10.7 \pm 3.0^{\mathrm{B}}$ & $2.6 \pm 2^{\mathrm{AC}}$ & $4.1 \pm 1.1^{\mathrm{A}}$ & $0.4 \pm 0.2^{\mathrm{C}}$ & $3.8 \pm 1.5^{\mathrm{A}}$ & $0.8 \pm 0.30^{\mathrm{C}}$ \\
\hline Ratio C:N & 52 & 65 & 145 & 189 & 303 & 749 & 258 & 395 \\
\hline $\begin{array}{l}{ }^{15} \mathrm{NO}_{3}{ }^{-} \text {-uptake } \\
{\left[\mathrm{mmol} \mathrm{h}^{-1} \mathrm{~g}^{-1}\right]}\end{array}$ & n.a & n.a & n.a & n.a & $0.92 \pm 0.16$ & $1.42 \pm 0.33$ & $0.96 \pm 0.17$ & $0.91 \pm 0.24$ \\
\hline \multicolumn{9}{|l|}{ Barley } \\
\hline $\begin{array}{l}\mathrm{C}[\mathrm{mmol} \\
\left.\mathrm{L}^{-1} \mathrm{~h}^{-1} \mathrm{~g}^{-1}\right]\end{array}$ & $1.64 \pm 0.33^{\mathrm{A}}$ & $0.42 \pm 0.13^{\mathrm{B}}$ & $1.12 \pm 0.62^{\mathrm{AC}}$ & $0.28 \pm 0.12^{\mathrm{B}}$ & $1.41 \pm 0.87^{\mathrm{AC}}$ & $0.81 \pm 0.71^{\mathrm{ABC}}$ & $0.99 \pm 0.19^{\mathrm{C}}$ & $0.34 \pm 0.05^{\mathrm{B}}$ \\
\hline $\begin{array}{l}\mathrm{N}[\mu \mathrm{mol} \\
\left.\quad \mathrm{L}^{-1} \mathrm{~h}^{-1} \mathrm{~g}^{-1}\right]\end{array}$ & $21.2 \pm 5.5^{\mathrm{A}}$ & $7.7 \pm 2.1^{\mathrm{BC}}$ & $14.5 \pm 7.6^{\mathrm{AB}}$ & $10.5 \pm 4.5^{\mathrm{BC}}$ & $9.6 \pm 8.3^{\mathrm{BC}}$ & $6.8 \pm 3.9^{\mathrm{BC}}$ & $3.3 \pm 1.0^{\mathrm{C}}$ & $6.7 \pm 2.0^{\mathrm{C}}$ \\
\hline Ratio C:N & 78 & 55 & 77 & 27 & 147 & 118 & 298 & 51 \\
\hline $\begin{array}{l}{ }^{15} \mathrm{NO}_{3}-\text { uptake } \\
{\left[\mathrm{mmol} \mathrm{h}^{-1} \mathrm{~g}^{-1}\right]}\end{array}$ & n.a & n.a & n.a & n.a & $0.87 \pm 0.18$ & $0.91 \pm 0.19$ & $0.81 \pm 0.05$ & $0.73 \pm 0.13$ \\
\hline \multicolumn{9}{|l|}{ Wheat } \\
\hline $\begin{array}{l}\mathrm{C}[\mathrm{mmol} \\
\left.\mathrm{L}^{-1} \mathrm{~h}^{-1} \mathrm{~g}^{-1}\right]\end{array}$ & $0.15 \pm 0.07^{\mathrm{A}}$ & $0.24 \pm 0.02^{\mathrm{A}}$ & $1.41 \pm 0.16^{\mathrm{B}}$ & $0.22 \pm 0.16^{\mathrm{A}}$ & $0.35 \pm 0.32^{\mathrm{A}}$ & $0.36 \pm 0.14^{\mathrm{A}}$ & $1.07 \pm 0.17^{\mathrm{C}}$ & $0.37 \pm 0.11^{\mathrm{A}}$ \\
\hline $\begin{array}{l}\mathrm{N}[\mu \mathrm{mol} \\
\left.\quad \mathrm{L}^{-1} \mathrm{~h}^{-1} \mathrm{~g}^{-1}\right]\end{array}$ & $3.9 \pm 1.3^{\mathrm{A}}$ & $6.1 \pm 2.2^{\mathrm{AC}}$ & $28.1 \pm 7.8^{\mathrm{B}}$ & $5.0 \pm 2.1^{\mathrm{AC}}$ & $3.8 \pm 2.6^{\mathrm{A}}$ & $4.7 \pm 1.1^{\mathrm{AC}}$ & $9.6 \pm 2.1^{\mathrm{C}}$ & $4.6 \pm 2.4^{\mathrm{C}}$ \\
\hline Ratio C:N & 38 & 39 & 50 & 43 & 93 & 76 & 111 & 81 \\
\hline $\begin{array}{l}{ }^{15} \mathrm{NO}_{3}-\text { uptake } \\
{\left[\mathrm{mmol} \mathrm{h}^{-1} \mathrm{~g}^{-1}\right]}\end{array}$ & n.a & n.a & n.a & n.a & $0.77 \pm 0.08^{\mathrm{AC}}$ & $1.15 \pm 0.24^{\mathrm{B}}$ & $0.61 \pm 0.08^{\mathrm{A}}$ & $0.84 \pm 0.11^{\mathrm{BC}}$ \\
\hline
\end{tabular}

The most abundant compounds in root exudates were quantified with standards (Table S3) to calculate total C and N values. Statistical differences within single rows are indicated by capital letters. Therefore, one-way ANOVAs $(P<0.05)$ were calculated and Fisher's Least Significant Test (LSD) was used as post hoc test to show differences among treatments. Given are mean values \pm SD of four or five replicated samples (specified in Table S2). Plants grown under 34/40\% WFPS were gassed with synthetic air to achieve aerobic conditions and plants grown under 50\% WFPS were gassed with $\mathrm{N}_{2}$ to achieve anaerobic conditions. The modified Hoagland solution used for plants grown in Rotthalmünster soil that had a tenfold higher phosphate contents than that used for plants grown in Gießen soil 
exudation which ranged between 0.4 and $28.1 \mu \mathrm{mol}$ $\mathrm{L}^{-1} \mathrm{~h}^{-1} \mathrm{~g}^{-1}$ root DW. Root exudation of both $\mathrm{C}$ and $\mathrm{N}$ containing compounds was highest in barley and lowest in wheat (C containing compounds), respectively ryegrass ( $\mathrm{N}$ containing compounds). Within most treatments, total $\mathrm{C}$ and $\mathrm{N}$ exudation decreased at elevated soil water content, i.e. under more anaerobic compared to aerobic conditions, particularly on Gießen soil. Total $\mathrm{C}$ and $\mathrm{N}$ exudation was highest in Gießen soil, particularly with plant roots incubated in distilled water. Total $\mathrm{C}$ rhizodeposition into distilled water was mostly higher into Hoagland solution, particularly for plants grown in Gießen soil. Within all treatments, root exudation of $\mathrm{N}$ containing compounds was higher in distilled water compared to Hoagland solution. Total $\mathrm{N}$ exudation was negatively correlated to ${ }^{15} \mathrm{NO}_{3}{ }^{-}$-uptake capacities across all plant species and treatments (Fig. S1). ${ }^{15} \mathrm{NO}_{3}{ }^{-}$-uptake capacities showed no soil or soil moisture effect in barley and ryegrass, but uptake capacities were increased at 50\% WFPS in wheat in both soils.

Heatmaps showed mostly increased root exudation for plants grown at low soil moisture levels (Fig. S2-4). The effect was less pronounced in ryegrass and barley for the organic acids pyruvate, citrate, fumarate and malate. In different soils, plant species showed mixed effects on root exudates. There was mostly reduced root exudation in Rotthalmünster compared to Gießen soil in ryegrass and wheat. In contrast, barley had mostly increased rhizodeposition at Rotthalmünster compared to Gießen soil. Plants incubated in distilled water compared to modified Hoagland solution showed mostly increased root exudation for amino acids and organic acids. Only pyruvate, alanine and leucine had mostly decreased root exudation into distilled water, particularly in barley and wheat. Carbohydrates showed mostly but not generally decreased root exudation into distilled water.

We compared the concentrations of most abundant quantified compounds in the incubation solution and in roots to show which compounds were actively exudated against concentration gradients into the incubation solution. Therefore, we calculated the root concentrations in mol L-1 based on the root hydration state of ryegrass, barley and wheat $(84 \pm 7 \%$ across plant species and treatments). Higher concentration of metabolites in incubation solution compared to root concentration were found for pyruvate, particularly in barley and wheat, and for fumarate in barley (Table S7). Increased concentrations were also found for lyxose (up to $98.6 \%$ of root lyxose concentration) and leucine (up to $89.9 \%$ of root leucine concentration). Lowest concentrations in the incubation solutions compared to the roots were observed for GABA and sucrose (both $<1 \%$ of root concentration).

Plant species, soil moisture and soil type determine the composition of root exudation

We correlated both concentrations of single compounds (Table S6-8) and bulk concentrations of amino acids, carbohydrates and organic acids (Fig. 1) in roots, shoots and root exudates of plants incubated in Hoagland solution. Metabolites identified in roots were mostly positively correlated to metabolites identified in shoots, particularly for carbohydrates and organic acids (Table S6-8). Overall, carbohydrates were mostly positively correlated in root and shoots to root exudates, particularly in ryegrass and barley. In contrast, amino acids and organic acids of shoot and root metabolites showed mostly no correlations or even negative correlations to root exudates, e.g. for wheat in Gießen soil (Fig. 1).

The composition of amino acids, carbohydrates and organic acids are shown across plant species and treatments to illustrate general differences between metabolites of shoots, roots and root exudates sampled in Hoagland solution and distilled water (Fig. 2). The main components $(>75 \%)$ of primary metabolites in shoots, roots and root exudates were carbohydrates (Fig. 2A). The composition of amino acids, carbohydrates and organic acids was similar in shoots and roots, but the proportion of organic acids was significantly decreased $(p<0.05)$ in root exudates of plants incubated in Hoagland solutions. Further, the proportion of amino acids was significantly increased $(p<0.05)$ in root exudates, when distilled water was used as sampling solution. The composition of quantified amino acids, carbohydrates and organic acids showed large differences between plant tissues and root exudates (Fig. 2B-D). Compared to shoots and roots, the composition of amino acids in root exudates showed increased proportions of leucine and alanine and decreased proportions of serine, threonine, norleucine and isoleucine. However, amino acids sampled in distilled water were more similar to shoot and root composition and showed significantly 
Fig. 1 Correlation analysis of root exudates, shoots and roots in ryegrass (a and $\mathbf{b}$ ), barley (c and d) and wheat (e and $\mathbf{f}$ ) in Rotthalmünster and Gießen soil. Concentrations of amino acids, organic acids and carbohydrates were $\log _{\mathrm{e}}$ normalized and metabolites of plants incubated in a modified Hoagland solution were used for correlation analysis. Significant simple linear regressions are indicated by $\mathrm{R}^{2}$-values $(P<0.05)$.

Regression lines with lower significance $(P<0.10)$ are displayed without $R^{2}$ values

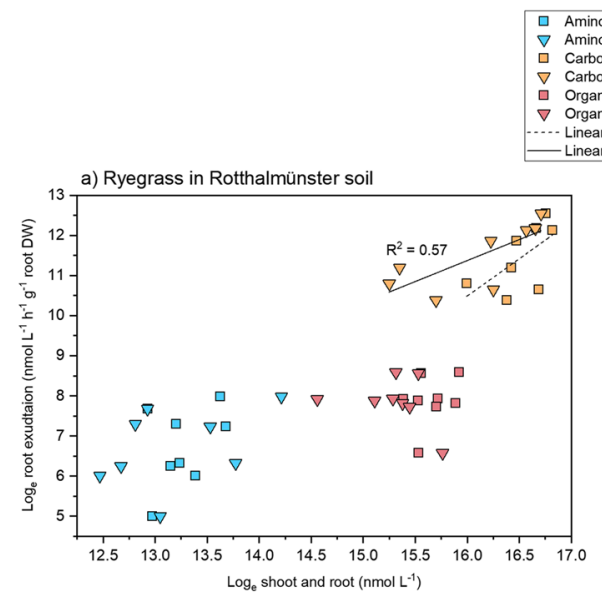

Amino acids shoot

Amino acids root
Carbohydrates shoo

Carbohydrates root

Organic acids shool

(n)

Lnear correlation shoo
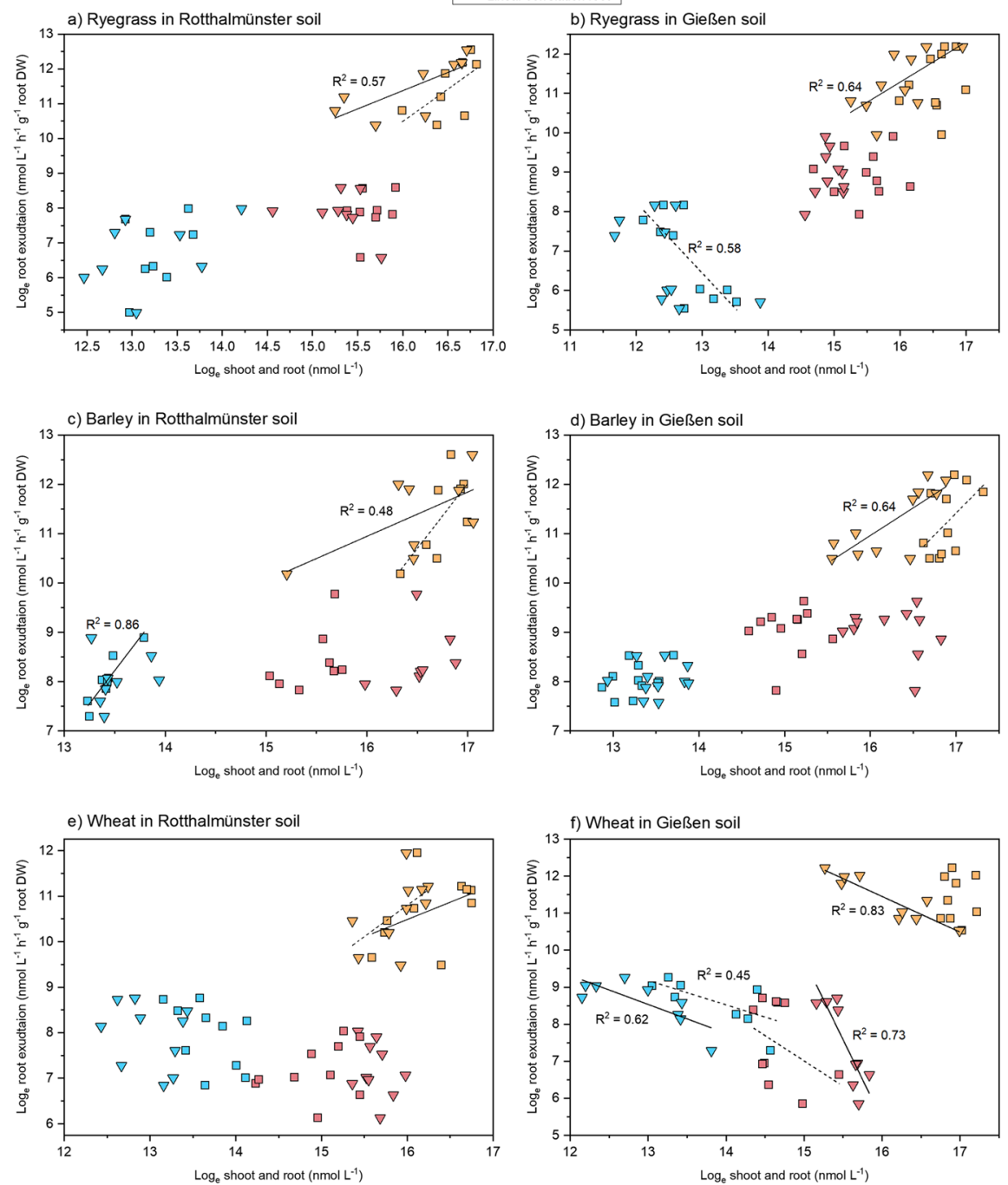

increased proportions of threonine, serine, norleucine and isoleucine compared to amino acids collected in modified Hoagland solution. The most abundant quantified carbohydrates showed a similar pattern in shoots and roots (Fig. 2C). In contrast, the proportion of sucrose was strongly decreased in root exudates compared to shoots and roots, while glucose and lyxose proportions were increased, particularly in root exudates collected in Hoagland solution. Malic acid and citric acid were the major organic acids and represented more than $80 \%$ of organic acids in all tissues (Fig. 2D). Roots and shoots showed significantly higher proportions of aspartic acid and GABA compared to root exudates collected in Hoagland solution and distilled water. In contrast, pyruvic acid, fumaric acid and pyroglutamic acid showed increased proportions in exudation solutions compared to roots and shoots, particularly in plants incubated in Hoagland solution.

The most abundant compounds exudated originated from several primary metabolic pathways, including glycolysis, citrate cycle, shikimate pathway and multiple pathways of amino acid synthesis (Figs. 3, 4, 5, 6 and 7). Rhizodeposition at 30/40\% 

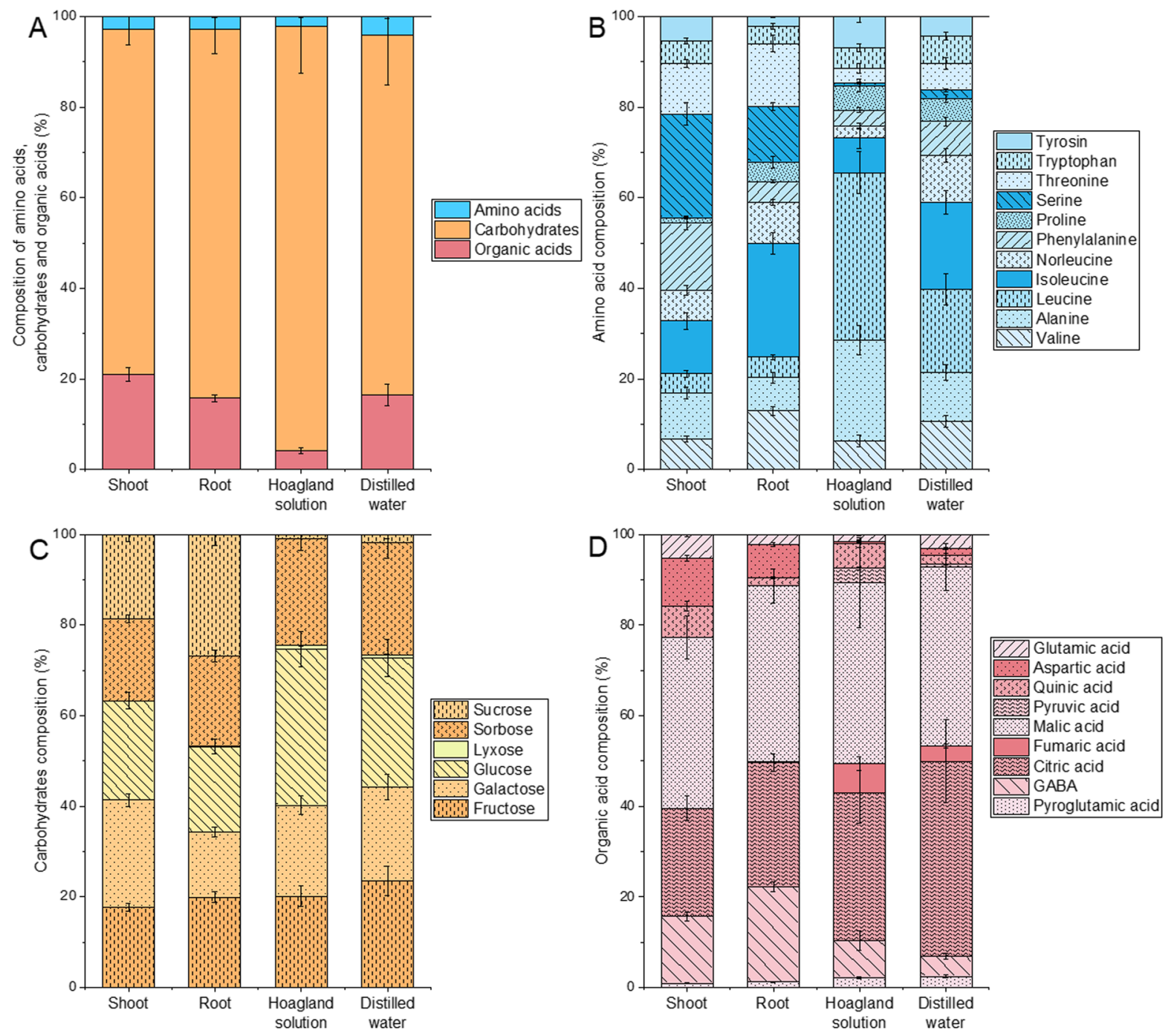

Fig. 2 Comparison of total amino acids, carbohydrates and organic acids (A), individual amino acids (B), individual carbohydrates (C) and individual organic acids (D) of shoot extracts, roots extracts, root exudates collected in a modi-

WFPS compared to 50\% WFPS in the soil showed consistent abundance of most metabolites originated from glycolysis in ryegrass and wheat (Fig. 3). Only the pyruvate concentration was reduced indicating reduced activity of pyruvate kinase at $34 / 40 \%$ WFPS. Despite mostly low concentrations of pyruvate and organic acids of the citrate cycle, amino acid contents of root exudates originating from pyruvate, 2-oxoglutarate and oxaloacetate were enhanced at $34 / 40 \%$ WFPS, particularly in Gießen soil. In barley, abundances of metabolites in the exudation solution were

fied Hoagland solution and root exudates sampled in distilled water. Results are presented as the percentage composition of compound $\mathrm{C}$ concentrations and are means $( \pm \mathrm{SE})$ of all plant species and treatments $(n=54)$

already reduced downstream of fructose 6-phosphate probably regulated by phosphofructokinase. The exudation of 2-oxoglutarate and most amino acids originating from this citrate cycle intermediate were stimulated, particularly in Rotthalmünster soil.

Compared to Gießen soil, root exudation by plants in Rotthalmünster soil showed mostly consistent concentrations of glycolysis intermediates up to pyruvate in all plant species studied, however, citrate concentrations were strongly reduced (Fig. 4). In ryegrass, exudation of organic acids of the citrate cycle and 

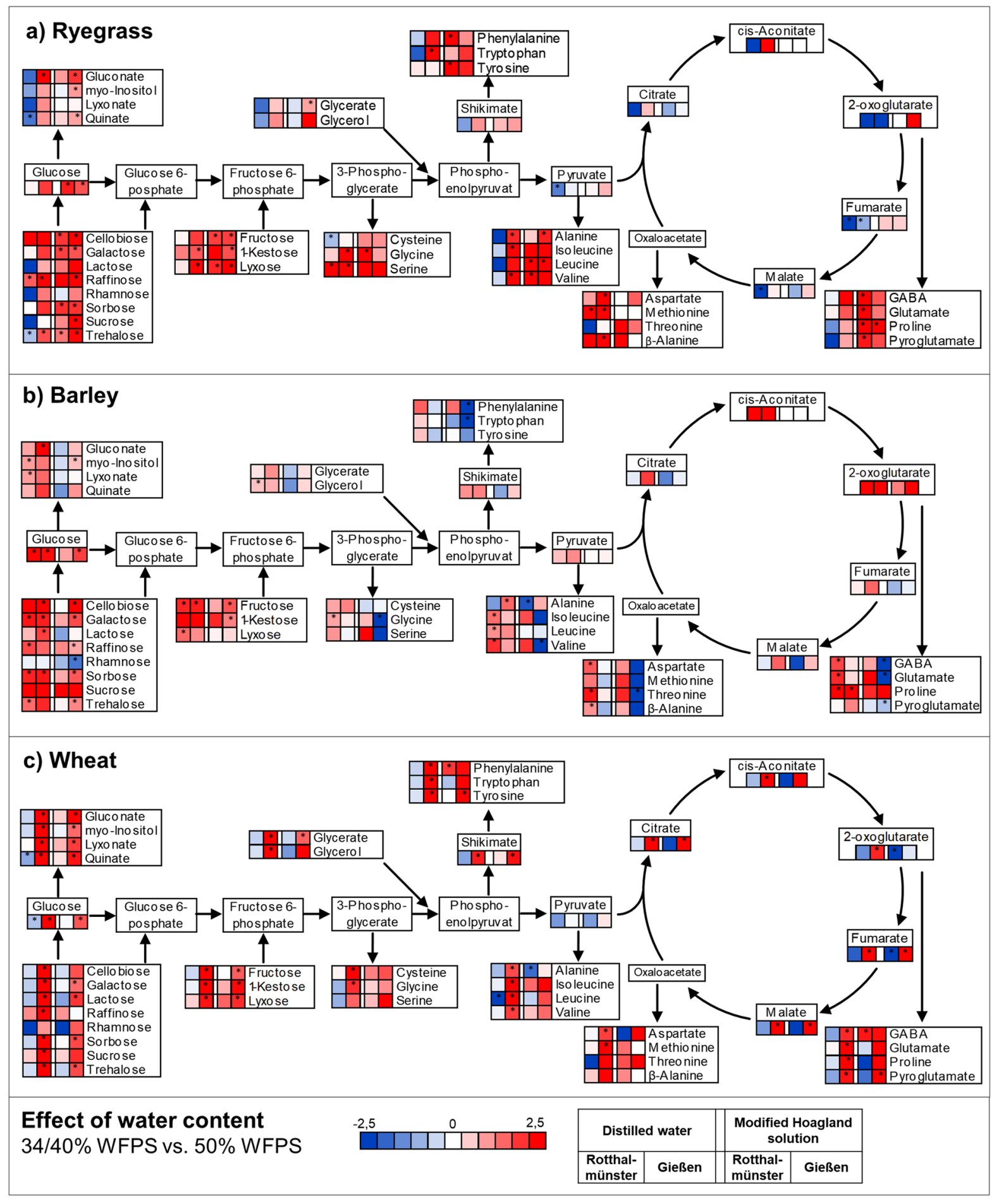

Fig. 3 Effect of water content on root exudates in ryegrass (a), barley (b) and wheat (c). Figure shows $\log _{2}$ values of fold changes of 34/40\% WFPS vs 50\% WFPS at the given colour scale. Left two squares: incubation with distilled water, right two squares: incubation with modified Hoagland solution. The left square of both treatments shows Rotthalmünster soil and the right square Gießen soil. Significant differences are indicated by asterisks $(P<0.05)$ after the Welch's unequal variances t-test 

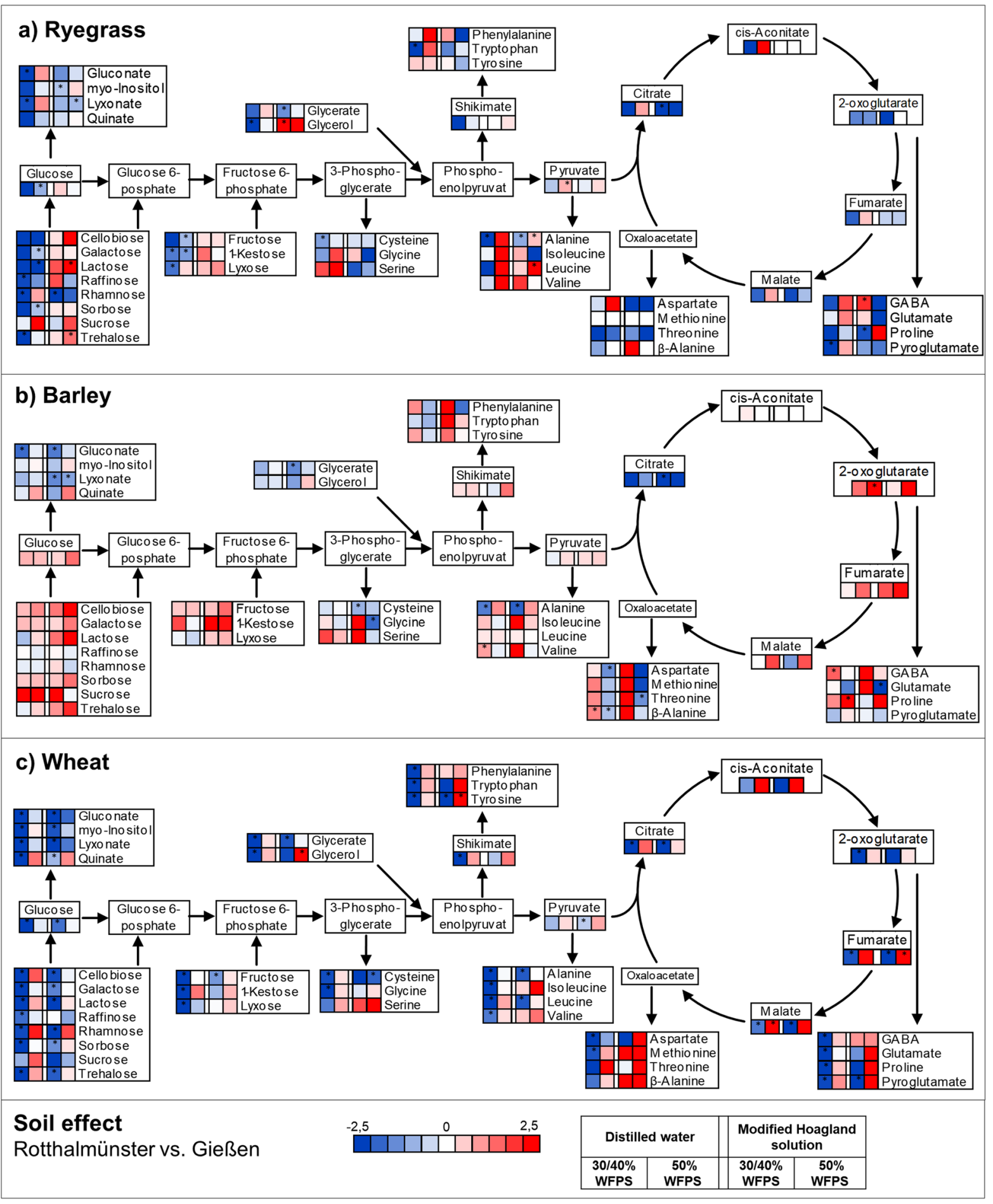

Fig. 4 Soil effects on root exudates in ryegrass (a), barley (b) and wheat (c). Figure shows $\log _{2}$ values of fold changes of $34 / 40 \%$ WFPS vs 50\% WFPS at the given colour scale. Left two squares: incubation with distilled water, right two squares: incubation with modified Hoagland solution. The left square of both treatments shows $34 / 40 \%$ WFPS and the right square $50 \%$ WFPS. Significant differences are indicated by asterisks $(P<0.05)$ after the Welch's unequal variances t-test 


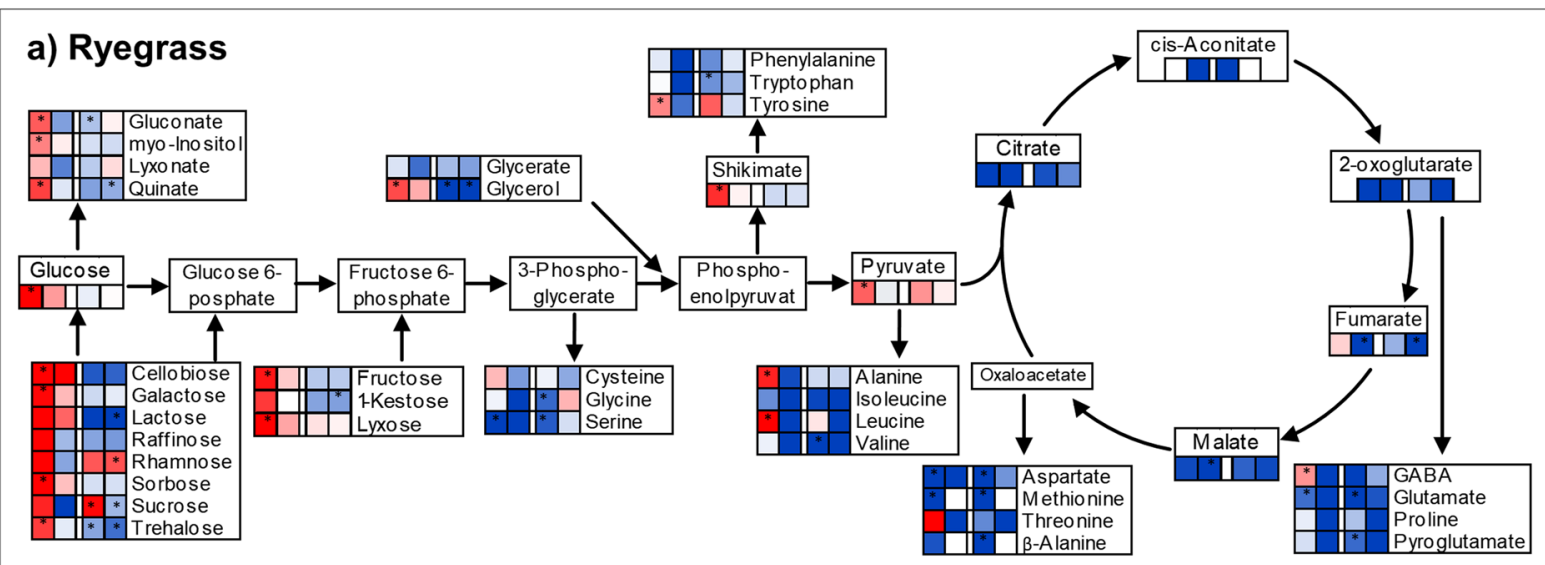

\section{b) Barley}
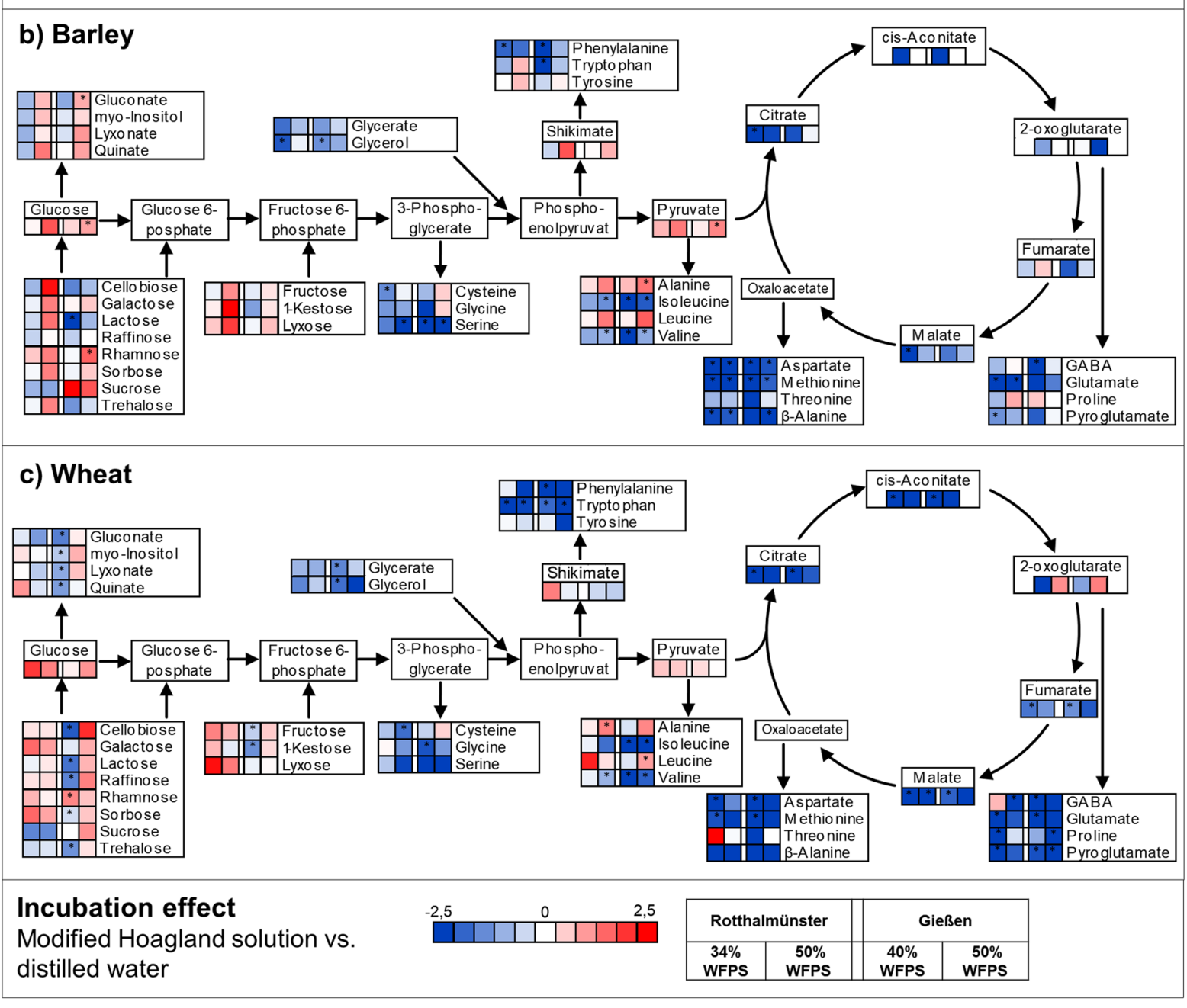

Fig. 5 Incubation effects on root exudates in ryegrass (a), barley (b) and wheat (c). Figure shows $\log _{2}$ values of fold changes of 34/40\% WFPS vs 50\% WFPS at the given colour scale. Left two squares: plants grown on Rotthalmünster soil, right two squares: plants grown on Gießen soil. The left square of both treatments shows $34 / 40 \%$ WFPS and the right square $50 \%$ WFPS. Significant differences are indicated by asterisks $(P<0.05)$ after the Welch's unequal variances t-test 

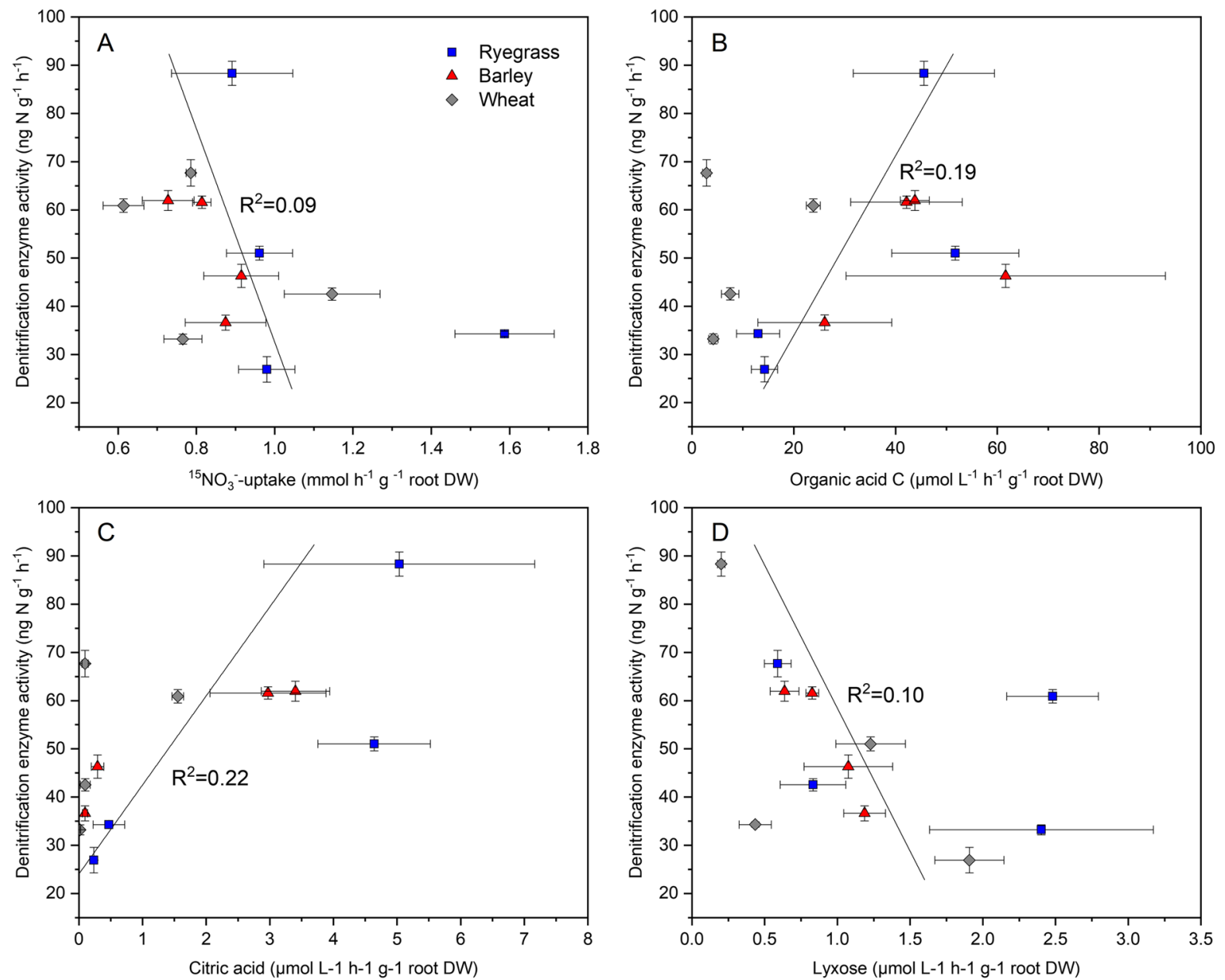

Fig. 6 Relationship between denitrification enzyme activity and ${ }^{15} \mathrm{NO}_{3}{ }^{-}$-uptake capacities (A), total organic acid concentration $(\mathbf{B})$, citric acid and $(\mathbf{C})$ and lyxose $(\mathbf{D})$. Metabolites of plants incubated in a modified Hoagland solution were used for

amino acids synthesised from citrate cycle intermediates remained reduced in Rotthalmünster compared to Gießen soil. In contrast, barley showed stimulated abundances of organic acids of the citrate cycle and amino acids produced from its intermediates in the exudation solution. In wheat, exudation of these metabolites was mostly higher than for the other species, particularly at 50\% WFPS in the soil.

In all plant species analysed, root exudation into Hoagland solution was lower compared to distilled water for metabolites downstream of fructose 6-phosphate (Fig. 5). Only root exudation of shikimate, pyruvate, alanine and leucine was increased, however, all further organic acids and amino acids produced correlation analysis. Displayed are mean values $( \pm \mathrm{SE})$ of each conducted treatment (both soil water contents and both soils). The regression line and $\mathrm{R}^{2}$ value originate from individual samples $(n=54)$

from these metabolites were exudated consistently in lower amounts.

Root exudation, nitrate uptake and denitrification enzyme activity (DEA)

Across all plants and soils, ${ }^{15} \mathrm{NO}_{3}{ }^{-}$-uptake capacities were negatively and organic acid exudation positively correlated to DEA (Fig. 6A and B). Among the most abundant compounds exudated, citric acid was positively correlated to DEA (Fig. 6C) and lyxose negatively correlated to DEA (Fig. 6D). The multiple linear regression model of quantified compounds with overall high 

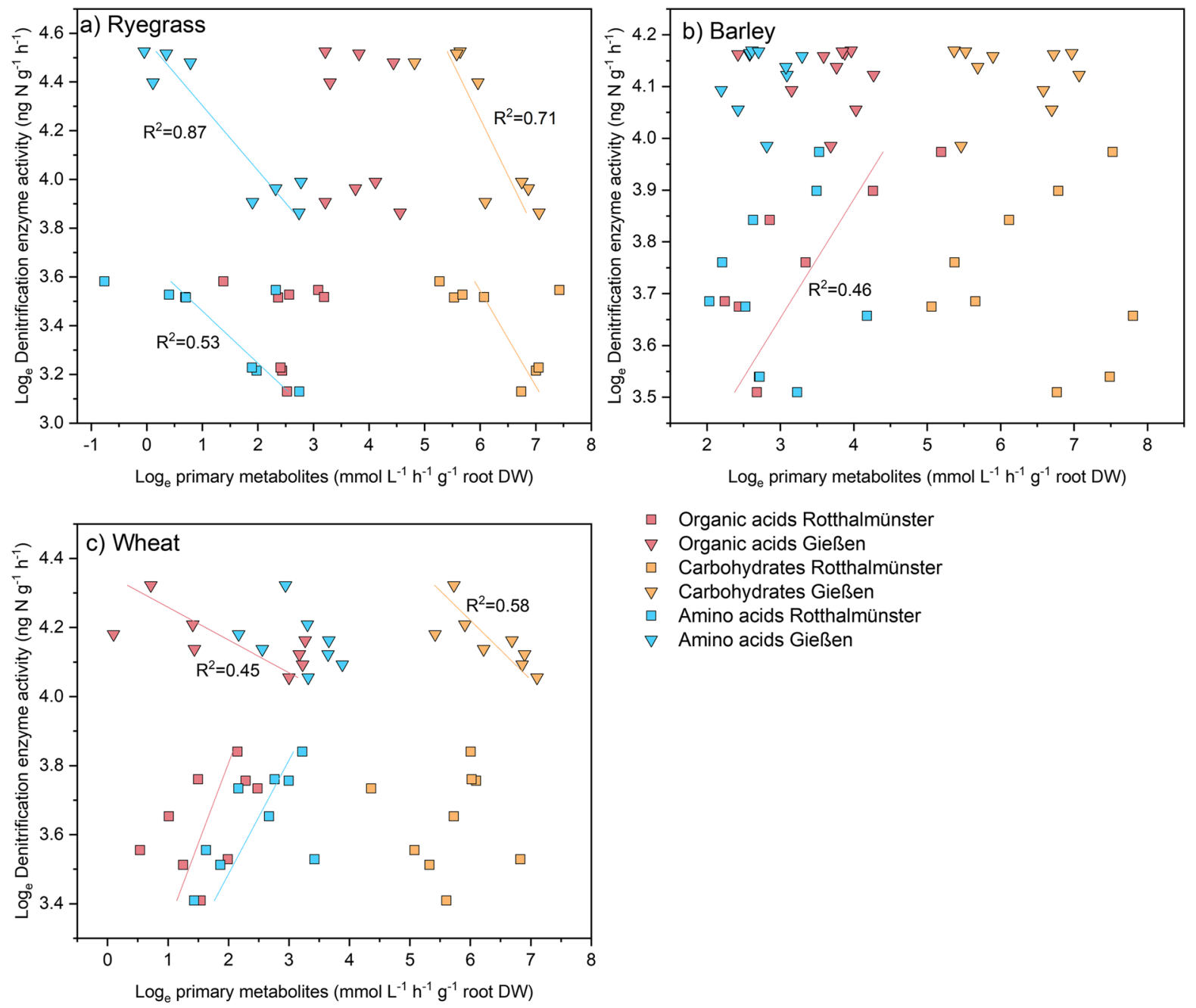

$\begin{array}{ll}\square & \text { Organic acids Rotthalmünster } \\ \nabla & \text { Organic acids Gießen } \\ \square & \text { Carbohydrates Rotthalmünster } \\ \nabla & \text { Carbohydrates Gießen } \\ \square & \text { Amino acids Rotthalmünster } \\ \nabla & \text { Amino acids Gießen }\end{array}$

Fig. 7 Relationship between denitrification enzyme activity and primary metabolites of root exudates in ryegrass, barley and wheat. Values of denitrification enzyme activity and concentrations of amino acids, organic acids and carbohydrates were $\log _{\mathrm{e}}$ normalized. Metabolites of plants incubated in a modified Hoagland solution were used for correlation analysis. Significant simple linear regressions are indicated by $\mathrm{R}^{2}$-values $(P<0.05)$. Regression lines with lower significance $(P<0.10)$ are displayed without $\mathrm{R}^{2}$ values predictive power $\left(\mathrm{R}^{2}=0.62\right)$ confirmed the negative impact of ${ }^{15} \mathrm{NO}_{3}{ }^{-}$-uptake and lyxose exudation but positive impact of citric acid exudation on DEA (Table 2). Furthermore, myo-Inositol and Leucine (positive relationship) and Proline and Glycerol (negative relationship) contributed explanatory power for DEA to this model. Many further metabolites showed correlations to DEA, however, mostly within particular plant species or soils; e.g. in ryegrass, many carbohydrates and amino acids showed negative correlations at Gießen soil to DEA, whereas many organic acids were positively correlated in barley at Rotthalmünster soil (Table S8). Bulk analysis of quantified amino acids, carbohydrates and organic acids also revealed negative correlations of amino acids and carbohydrates in ryegrass in both soils (Fig. 7). In contrast, barley showed no further correlations apart from the positive correlation of carbohydrates in Rotthalmünster soil. In wheat, organic acid was positively correlated to DEA in Rotthalmünster and negatively correlated to DEA in Gießen soil. Those negative 
Table 2 Multiple Regression analysis for the influence of root exudation and ${ }^{15} \mathrm{NO}_{3}{ }^{-}$-uptake capacities on denitrification enzyme activity (DEA)

\begin{tabular}{llllr}
\hline & $\begin{array}{l}\text { Regression } \\
\text { coefficient }\end{array}$ & Standard error & & \\
& & t value & $\mathrm{p}$ value \\
\hline $\mathrm{NO}_{3}{ }^{-}$-uptake & -21.927 & 7.188 & -3.051 & $<0.01$ \\
Citric acid & 1.885 & 0.506 & 3.728 & $<0.001$ \\
Glycerol & -0.964 & 0.406 & -2.371 & 0.022 \\
myo-Inositol & 7.196 & 3.520 & 2.044 & 0.047 \\
Leucine & 4.898 & 1.364 & 3.592 & $<0.001$ \\
Lyxose & -6.451 & 1.273 & -5.067 & $<0.001$ \\
Proline & -8.366 & 2.742 & -3.051 & $<0.01$ \\
\hline
\end{tabular}

$\mathrm{R}^{2}: 0.62, P<0.001$
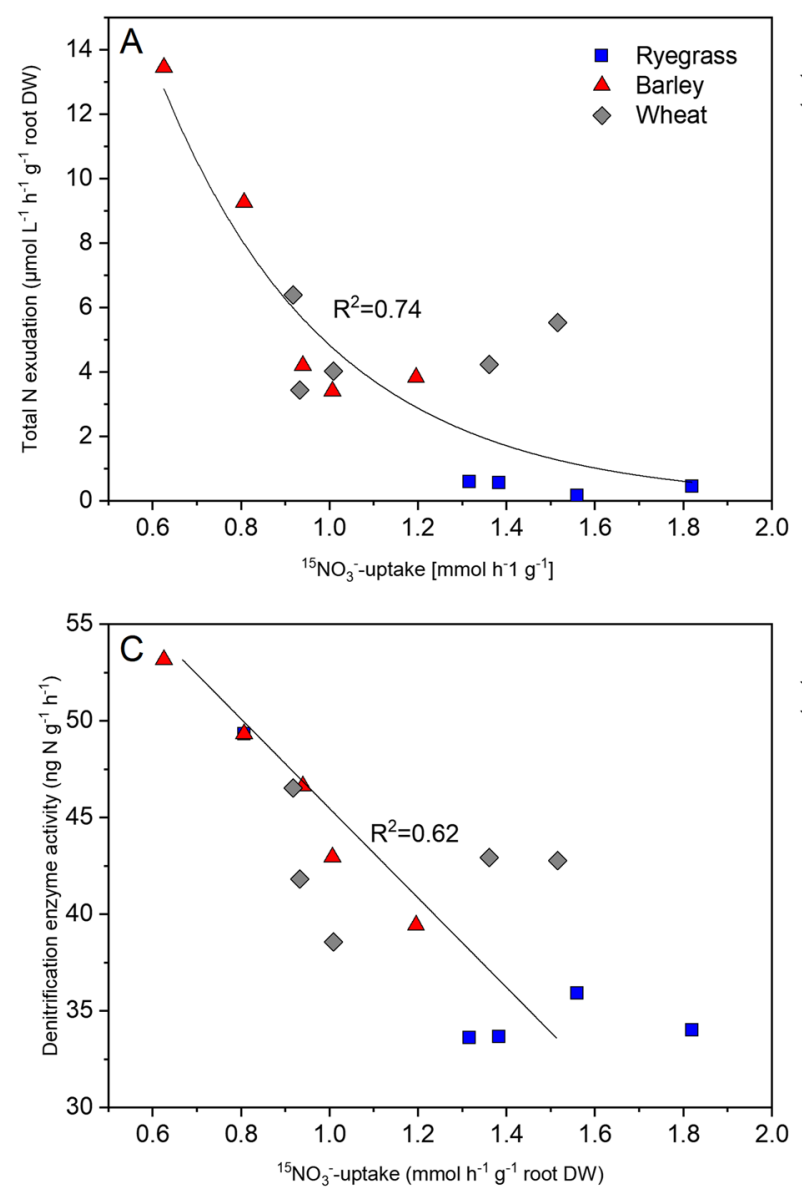

Fig. 8 Relationship between total $\mathrm{N}$ exudation and ${ }^{15} \mathrm{NO}_{3}{ }^{-}$uptake capacities (A), denitrification enzyme activity (DEA) and total $\mathrm{N}$ exudation (B), DEA and ${ }^{15} \mathrm{NO}_{3}{ }^{-}$-uptake capacities (C) and DEA and total C exudation (D) in Rotthalmünster soil or positive correlations in different soils were also shown for single organic acids like fumaric acid and malic acid (Table S8).

A comparative analysis of nitrate conversion rates by denitrifiers with nitrate uptake capacities of the roots and total $\mathrm{C}$ and $\mathrm{N}$ exudation across ryegrass, barley and wheat revealed well significant $(P<0.01)$ correlations at 50\% WFPS in Rotthalmünster soil (Fig. 8), but not at Gießen soil. Negative correlations of DEA and $\mathrm{N}$ exudation with ${ }^{15} \mathrm{NO}_{3}{ }^{-}$-uptake capacities (Fig. 8A and C), were also observed across all plant species and soils (Fig. 6A, Fig. S1), but with much lower explanatory power and significance. Additionally, total $\mathrm{N}$ and $\mathrm{C}$ exudation strongly stimulated DEA across all plant species at Rotthalmünster soil and 50\% WFPS (Fig. 8B and D).
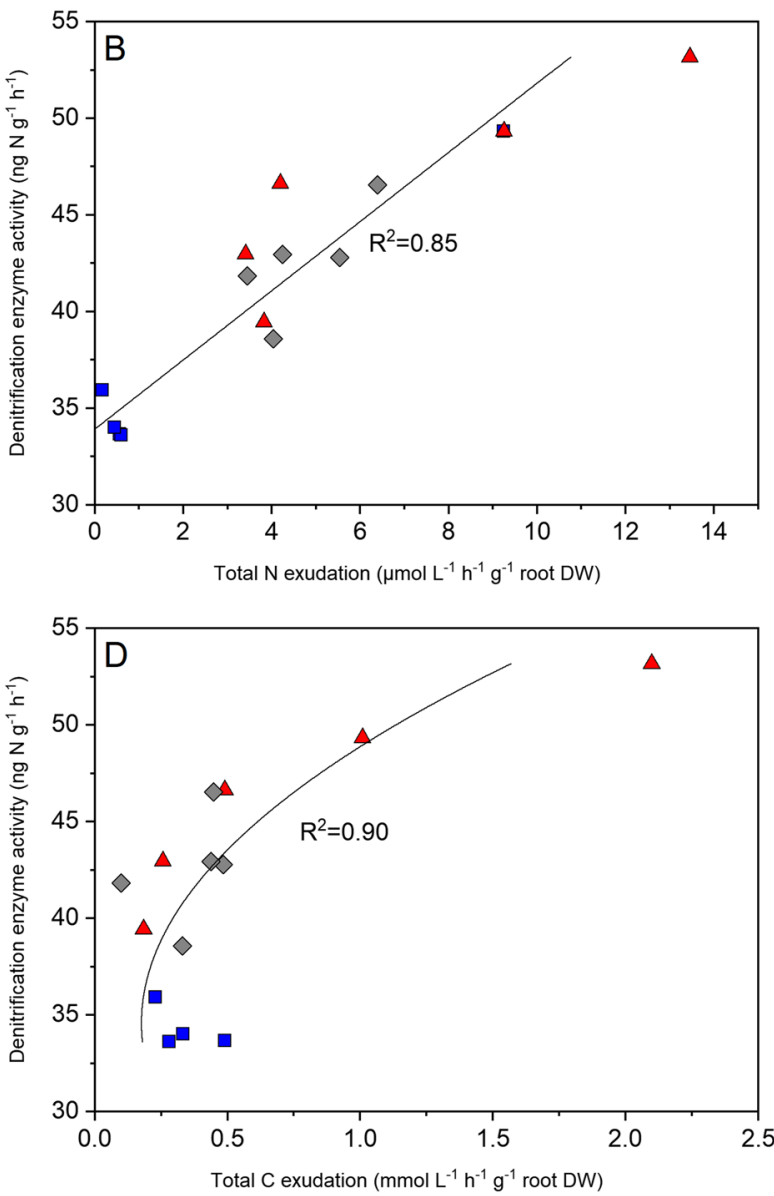

at high soil moisture level. Significant $(P<0.05)$ simple linear regressions (B and $\mathbf{C}$ ) and exponential regressions (A and $\mathbf{D})$ are displayed 


\section{Discussion}

Our study shows that root exudation of primary metabolites largely depends on plant species, soil type, soil moisture level and root exudation medium. Apparently, both soil and plant parameters interactively drive and regulate root exudation.

Methodological considerations - effects of incubation media on quantification of root exudation

In our experiment, plants were grown in the soil (and DEA was measured in the soil), while exudated compounds were collected in liquid solutions. This is a common approach, but of course only an approximation to the actual exudation into soil. The selection of the liquid solutions and the incubation time can also have a large impact on measured exudation rates. In our experiment, plants were either incubated for $2 \mathrm{~h}$ in distilled water or in a modified Hoagland solution. Previous studies reported highest concentration of root exudates incubated in distilled water compared with other sampling solutions (Aulakh et al. 2001a; Valentinuzzi et al., 2015). However, only Aulakh et al. (2001a) compared distilled water to a nutrient solution, but reported interference in the analysis of TOC by the wet digestion method and of organic acids by HPLC. In contrast, our study did not show any interference with compounds of the nutrient solution during GC-MS analysis of root exudates. Therefore, we could identify differences in root exudation between collection in distilled water compared to a nutrient solution with plants grown under the same growth conditions. Our results show large differences between incubation solutions in both total $\mathrm{C}$ (up to fivefold) and total $\mathrm{N}$ (up to 15-fold) exudation (Table 1), but also for individual compounds (Fig. 5 and Fig. S 2-4). Interestingly, many carbohydrates and some organic acids and amino acids were exudated in higher amounts into the nutrient solution than into distilled water. We expected higher exudation rates into distilled water due to the strong concentration gradient (Aulakh et al. 2001a). They indicate that root exudation of most carbohydrates and some organic acids and amino acids are actively controlled by plant roots. Apparently, nutrient solutions are well suited for root exudation sampling in connection with GC-MS analysis and constitute a more realistic approach for the evaluation of root exudation, particularly if simulated soil solutions are applied.

Soil type and soil moisture regulate root exudation

We hypothesized, that plant species, soil moisture and soil type determine root exudation. In our experiment root exudation of total $\mathrm{C}$ (up to sevenfold), total $\mathrm{N}$ (up to fivefold), and most compounds were increased under $34 / 40 \%$ WFPS compared to 50\% WFPS, but this response was also largely depending on plant species and soil type (Table 1, Fig. 3 and Fig. S2-4). Similarly, other recent studies showed increased exudation of carbohydrates (Canarini et al. 2016; Preece et al. 2018; Calvo et al. 2019), amino acids (Canarini et al. 2016; Bobille et al. 2019), organic acids (Canarini et al. 2016) and secondary metabolites (Gargallo-Garriga et al. 2018) at low soil water contents. Canarini et al. (2016) also showed species specific responses at different soil water contents. At low water content, soybean showed mostly increased exudation, whereas sunflower maintained root exudation at modified exudate composition. In contrast to the present study, where the soil type largely influenced effects of soil water content on root exudation, Gargallo-Garriga et al. (2018) did not observe differences of drought effects across three different soils. However, all these studies simulated drought events with much stronger reduced water contents than this study.

For the present experiments, plants were grown on SOC rich clay loam referred to as Gießen soil and on SOC poorer silty loam referred to as Rotthalmünster soil. Between these soils, root exudation differed for up to $1000 \%$ for total C and for up to $700 \%$ for total $\mathrm{N}$ with higher root exudation in the more $\mathrm{C}$ - and $\mathrm{N}$-rich Gießen grassland soil (Table 1). This soil effect was modulated by plant species and soil water content, e.g. root exudation was mostly significantly reduced in Rotthalmünster compared to Gießen, but only in ryegrass and wheat and only for 34/40\% WFPS (Table 1, Fig. 4 and Fig S2-4). Neumann et al. (2014) analyzed root exudates of lettuce on three different soils. Similar to our study, they reported that root exudation varied largely quantitatively, but not qualitatively between the different soils. From this result it was concluded that root exudation is most likely driven by different microbial populations in the soil. In our study, we could illustrate that soil moisture largely influences the effect of different soils on root 
exudation, which also could be explained by altered microbiome composition in the rhizosphere.

\section{Plant mechanisms of root exudation}

We could illustrate strong plant control on root exudation of the organic acids pyruvate and fumarate (Table S7). Active transport of the organic acids citrate and malate through MATE and ALMT transporters have been described in published literature (Canarini et al. 2019; Vives-Peris et al. 2019). Recently, Maruyama et al. (2019) demonstrated that ALMT transporters were activated in response to $\mathrm{P}$ deficiency. It is assumed by the authors that further uncharacterized MATE/ALMT family members transport other organic acids through the plasma membrane (Sasse et al. 2018). Pyruvate and fumarate, which have been found in increased concentration in incubation solutions in our experiment, could have been transported actively by undescribed MATE/ ALMT family members.

The amino acid leucine and the carbohydrate lyxose were also exudated in high amounts in the present study, indicating active exudation or at least strong control of root exudation by the investigated grass species (Table S7). Further evidence for plant control on root exudation was revealed by the comparison of exudation into Hoagland solution and distilled water (Fig. 5). Not only exudation of pyruvate, leucine and lyxose were mostly increased by incubation of the roots in Hoagland solution, but also shikimate, alanine and a range of carbohydrates. Still correlation analysis of root exudates, shoots and roots revealed little correlations of total amino acid and organic acid concentrations and also for individual amino acids and organic acids (Fig. 1, Table S6-8). Almost all amino acids and most organic acids were found in different proportion in root exudates compared to roots. Different amino acids composition in root exudates and root extracts were reported previously (Lesuffleur and Cliquet 2010; Li et al. 2018). In addition, Li et al. (2018) did not observe correlations for organic acids, but positive correlations for carbohydrates in roots compared to root exudates. Similar to our study, Canarini et al. (2016) found a strong link between carbohydrates in root exudates and roots. In the present study, the composition of quantified carbohydrates revealed increased proportions of glucose and lyxose and decreased proportions of sucrose in root exudates compared to roots. This was confirmed by correlation analysis, where glucose, sucrose and lyxose showed almost no positive relation across all plant species and treatments. Additionally, the increased carbohydrate exudation by roots incubated in Hoagland solution compared to distilled water illustrates strong regulation of root exudation by plants. Apparently, plants must possess strong control mechanisms for root exudation, even if the transport through the root plasma membrane is driven mainly by diffusion (Canarini et al. 2019).

Regulation of DEA by root exudation

Malique et al. (2019) determined the Denitrification Enzyme Activity (DEA) in the rhizosphere soil within all treatments analysed in the present study. They showed that soil taken from the grassland site at Gießen had higher DEA than soil from an arable site at Rotthalmünster with differences being largest at $50 \%$ WFPS. Higher rates of DEA were explained with higher total $\mathrm{C}$ and $\mathrm{N}$ values and the clay loam texture in Gießen soil. All three plant species stimulated DEA and this effect was most pronounced at Rotthalmünster soil. We compared denitrifying activity determined by Malique et al. (2019) with root exudation of primary metabolites determined in the present study and hypothesized, that root exudation determines DEA. This was confirmed: across plant species and treatments total organic acid exudation stimulated DEA rates (Fig. 6B). Among the most abundant individual compounds, citric acid showed the most significant stimulation effect on denitrification, whereas lyxose seemed to inhibit denitrification (Fig. 6C and D, Table 2). A multiple regression model confirmed these compound-specific effects and - together with plant $\mathrm{NO}_{3}{ }^{-}$-uptake - explained $62 \%$ of the variability of DEA. This model of high explanatory power suggests a key role of composition of root exudation in the regulation of rhizosphere DEA and also supports the view that exudated compounds can either exert stimulating or inhibitory effects on denitrification. It needs to be noted that such effects can also be more indirect, i.e., originate from links between root exudation and nitrification such as e.g., biological nitrification inhibition and associated effects on denitrification $\mathrm{N}$ substrates (O'Sullivan et al. 2016). However, the large nitrate concentrations in the investigated agricultural soils, and the 
observation that links between root exudation and DEA were more pronounced at higher than at lower WFPS indicate a dominance of direct effects of root exudation on DEA.

Previously, higher stimulation of denitrification was demonstrated for organic acids compared to carbohydrates and amino acids (Henry et al. 2008; Morley et al. 2014). The particular importance of organic acids was also demonstrated by Guyonnet et al. (2017), who showed positive correlations of two organic acids with rates of DEA in root adhering soil (RAS). Additionally, a negative relationship between xylose and denitrification rates was measured. The carbohydrate xylose has a strong structural similarity to lyxose (lyxose is a C'-2 carbon epimer of xylose), which inhibited denitrification in our experiments. However, Guyonnet et al. (2017) measured root exudation in RAS, whereby in their study the surrounding bulk soil contained even higher abundances of xylose. However, it remains unknown if lyxose directly inhibits denitrifiers or if it shifts the competitive balance of heterotrophic soil microorganisms at the expense of denitrifiers and in favour of other heterotrophs. A reason for plants to stimulate denitrifiers could be to promote microbes which are able to metabolize intermediates, which are particularly formed under anaerobic conditions in the soil. On the other hand, citric acid and other organic acids could be mainly exudated by plants to mobilize nutrients in the soil. In this case, the stimulation of denitrifiers would be a probably unwanted side effect, since denitrification increases the competition for $\mathrm{N}$ compounds.

In the present study, plants not only influenced DEA by the release of primary metabolites, but also by nitrate uptake, which was negatively related to denitrification rates (hypothesis iv) (Fig. 6A, Table 2). This indicates that plants were competing for nitrate with denitrifying bacteria also in the rather $\mathrm{N}$ rich agricultural soils of this study. Previously, Moreau et al. (2015) found a similar negative relation of nitrate uptake and denitrifying bacteria activity, however, only at high soil nitrate contents. In contrast, we found a much stronger link of nitrate uptake and DEA at Rotthalmünster soil (Fig. 8C), which had lower soil nitrate concentrations after 30 days of plant growth compared to Gießen soil (Malique et al. 2019).

However, depending on plant species and soil type, we observed that the same compound could exhibit positive or negative effects on DEA (hypothesis iii)
(Fig. 7, Table S8). These differences are probably caused by different soil-inherent denitrifier communities that are largely influenced by both soil total $\mathrm{C}$ and $\mathrm{N}$ contents, which stimulate microbial and denitrifying activity in soils (Burford and Bremner 1975; Smith and Tiedje 1979; Klemedtsson et al. 1991; Philippot et al. 2009). Addition of $\mathrm{C}$ and $\mathrm{N}$ to different soils only increased denitrifying activity in $50-70 \%$ of the studied soils which is probably linked to differences in the $\mathrm{C}$ and $\mathrm{N}$ status (Florio et al. 2017, 2019). Different total C and N contents in Rotthalmünster and Gießen soil could also explain different plant effects on DEA rates in our experiment. Gießen soil has 3.6 times higher total $\mathrm{C}$ and 3.2 higher total $\mathrm{N}$ content than Rotthalmünster soil. Under these conditions, root exudation of primary metabolites seemed not to increase denitrification rates in Gießen soil, whereas in Rotthalmünster soil root exudation was often positively correlated to denitrifying activity (Fig. 7, Table S8). Consequently, plant effects on denitrifiers were higher in Rotthalmünster soil (Fig. 8).

\section{Conclusions}

The present study shows that root exudation of primary metabolites largely depends on plant species, soil type, soil moisture level and root exudation medium. Despite the strong concentration gradient of distilled water, many carbohydrates and some organic acids and amino acids were exudated in higher amounts into the nutrient solution than into distilled water. To a large extent, plants were able to control root exudation, particularly of amino acids and organic acids, and pyruvate and fumarate were even exudated actively against the concentration gradient of the incubation solution. In this context, root exudates can either stimulate or inhibit rhizosphere DEA depending on chemical species and soil microbial community. Specifically, regulation of denitrification by root exudates appears to be more pronounced in low $\mathrm{C}$ soils and under higher soil water content. Overall, root exudation of organic acids showed stimulation effects, and lyxose exudation seemed to inhibit denitrifying activity. Additionally, nitrate uptake and denitrification rates were negatively correlated, which illustrate the competition for $\mathrm{N}$ between plants and microbes even in the investigated agricultural soils with comparably high $\mathrm{N}$ availability. Overall, our 
results reveal, that both physicochemical soil parameters as well as species-specific plant metabolism interactively drive and regulate root exudation, and thus denitrification activity in the rhizosphere. Combining measurements of root exudation under different soils and environmental conditions (e.g., light, soil moisture) with direct measurements of actual denitrification and its $\mathrm{N}$ gas product ratio in intact plant-soil microbe systems would further advance our understanding of these important plant-soil-microbe interactions, but are still complicated by methodological problems in direct $\mathrm{N}_{2}$ emission measurements. The present information on composition and contents of root exudates reflects the situation at the vegetative growth stage of the plants. It is expected that root exudation changes during plant development particularly at flowering and during seed production, but further research is required to characterize these changes.

Funding Open Access funding enabled and organized by Projekt DEAL. This work if funded by the Deanship of Scientific Research at King Saud University, Saudi Arabia through research group. RG-1435-018. This work was also funded through the DFG research unit DASIM.

Data availability The datasets generated during and/or analysed during the current study are available from the corresponding author on reasonable request.

Code availability Not applicable.

\section{Declarations}

Conflict of interest No conflicts of interest.

Open Access This article is licensed under a Creative Commons Attribution 4.0 International License, which permits use, sharing, adaptation, distribution and reproduction in any medium or format, as long as you give appropriate credit to the original author(s) and the source, provide a link to the Creative Commons licence, and indicate if changes were made. The images or other third party material in this article are included in the article's Creative Commons licence, unless indicated otherwise in a credit line to the material. If material is not included in the article's Creative Commons licence and your intended use is not permitted by statutory regulation or exceeds the permitted use, you will need to obtain permission directly from the copyright holder. To view a copy of this licence, visit http://creativecommons.org/licenses/by/4.0/.

\section{References}

Aulakh MS, Wassmann R, Bueno C et al (2001a) Characterization of root exudates at different growth stages of ten rice (Oryza sativa L.) cultivars. Plant Biol 3:139-148. https:// doi.org/10.1055/s-2001-12905

Aulakh MS, Wassmann R, Bueno C, Rennenberg H (2001b) Impact of root exudates of different cultivars and plant development stages of rice (Oryza sativa L.) on methane production in a paddy soil. Plant Soil 230:77-86. https:// doi.org/10.1023/A:1004817212321

Bardon C, Piola F, Bellvert F et al (2014) Evidence for biological denitrification inhibition (BDI) by plant secondary metabolites. New Phytol 204:620-630. https://doi.org/10. 1111/nph.12944

Bardon C, Misery B, Piola F et al (2018) Control of soil N cycle processes by Pteridium aquilinum and Erica cinerea in heathlands along a pH gradient. Ecosphere 9:e02426. https://doi.org/10.1002/ecs2.2426

Bobille H, Fustec J, Robins RJ et al (2019) Effect of water availability on changes in root amino acids and associated rhizosphere on root exudation of amino acids in Pisum sativum L. Phytochemistry 161:75-85. https://doi.org/10. 1016/j.phytochem.2019.01.015

Burford JR, Bremner JM (1975) Relationships between the denitrification capacities of soils and total, water-soluble and readily decomposable soil organic matter. Soil Biol Biochem 7:389-394. https://doi.org/10.1016/00380717(75)90055-3

Calvo OC, Franzaring J, Schmid I, Fangmeier A (2019) Root exudation of carbohydrates and cations from barley in response to drought and elevated $\mathrm{CO} 2$. Plant Soil 438:127-142. https://doi.org/10.1007/ s11104-019-03998-y

Canarini A, Merchant A, Dijkstra FA (2016) Drought effects on Helianthus annuus and Glycine max metabolites: from phloem to root exudates. Rhizosphere 2:85-97. https:// doi.org/10.1016/j.rhisph.2016.06.003

Canarini A, Kaiser C, Merchant A et al (2019) Root exudation of primary metabolites: mechanisms and their roles in plant responses to environmental stimuli. Front Plant Sci 10:157. https://doi.org/10.3389/fpls.2019.00157

Chapman SK, Langley JA, Hart SC, Koch GW (2006) Plants actively control nitrogen cycling: uncorking the microbial bottleneck. New Phytol 169:27-34. https://doi.org/10. 1111/j.1469-8137.2005.01571.x

Chong J, Yamamoto M, Xia J (2019) MetaboAnalystR 2.0: from raw spectra to biological insights. Metabolites 9:57. https://doi.org/10.3390/metabo9030057

Dannenmann M, Simon J, Gasche R et al (2009) Tree girdling provides insight on the role of labile carbon in nitrogen partitioning between soil microorganisms and adult European beech. Soil Biol Biochem 41:1622-1631. https://doi. org/10.1016/j.soilbio.2009.04.024

Derrien D, Marol C, Balesdent J (2004) The dynamics of neutral sugars in the rhizosphere of wheat. An approach by 13C pulse-labelling and GC/C/IRMS. Plant Soil 267:243253. https://doi.org/10.1007/s11104-005-5348-8 
Dietz S, Herz K, Döll S et al (2019) Semi-polar root exudates in natural grassland communities. Ecol Evol 9:55265541. https://doi.org/10.1002/ece3.5043

Fasbender L, Maurer D, Kreuzwieser J et al (2017) The carnivorous Venus flytrap uses prey-derived amino acid carbon to fuel respiration. New Phytol 214:597-606. https://doi. org/10.1111/nph.14404

Florio A, Pommier T, Gervaix J et al (2017) Soil C and N statuses determine the effect of maize inoculation by plant growth-promoting rhizobacteria on nitrifying and denitrifying communities. Sci Rep 7:1-12. https://doi.org/10. 1038/s41598-017-08589-4

Florio A, Bréfort C, Gervaix J et al (2019) The responses of $\mathrm{NO} 2--$ and N2O-reducing bacteria to maize inoculation by the PGPR Azospirillum lipoferum CRT1 depend on carbon availability and determine soil gross and net N2O production. Soil Biol Biochem 136:107524. https://doi. org/10.1016/j.soilbio.2019.107524

Gargallo-Garriga A, Preece C, Sardans J et al (2018) Root exudate metabolomes change under drought and show limited capacity for recovery. Sci Rep 8:1-15. https://doi.org/10. 1038/s41598-018-30150-0

Graf DRH, Saghaï A, Zhao M et al (2019) Lucerne (Medicago sativa) alters N2O-reducing communities associated with cocksfoot (Dactylis glomerata) roots and promotes N2O production in intercropping in a greenhouse experiment. Soil Biol Biochem 137:107547. https://doi.org/10.1016/j. soilbio.2019.107547

Guyonnet JP, Vautrin F, Meiffren G et al (2017) The effects of plant nutritional strategy on soil microbial denitrification activity through rhizosphere primary metabolites. FEMS Microbiol Ecol 93:1-11. https://doi.org/10.1093/femsec/ fix022

Haichar F el Z, Santaella C, Heulin T, Achouak W (2014) Root exudates mediated interactions belowground. Soil Biol Biochem 77:69-80. https://doi.org/10.1016/j.soilbio.2014.06. 017

Henry S, Texier S, Hallet S et al (2008) Disentangling the rhizosphere effect on nitrate reducers and denitrifiers: Insight into the role of root exudates. Environ Microbiol 10:3082-3092. https://doi.org/10.1111/j.1462-2920.2008.01599.x

Jacoby R, Peukert M, Succurro A et al (2017) The role of soil microorganisms in plant mineral nutrition - current knowledge and future directions. Front Plant Sci 8:1-19. https:// doi.org/10.3389/fpls.2017.01617

Klemedtsson L, Simkins S, Svensson BH et al (1991) Soil denitrification in three cropping systems characterized by differences in nitrogen and carbon supply - II. Water and NO3 effects on the denitrification process. Plant Soil 138:273286. https://doi.org/10.1007/BF00012254

Kreuzwieser J, Hauberg J, Howell KA et al (2009) Differential response of gray poplar leaves and roots underpins stress adaptation during hypoxia. Plant Physiol 149:461-473. https://doi.org/10.1104/pp.108.125989

Lesuffleur F, Cliquet JB (2010) Characterisation of root amino acid exudation in white clover (Trifolium repens L.). Plant Soil 333:191-201. https://doi.org/10.1007/ s11104-010-0334-1

Li X, Dong J, Chu W et al (2018) The relationship between root exudation properties and root morphological traits of cucumber grown under different nitrogen supplies and atmospheric CO2 concentrations. Plant Soil 425:415-432. https://doi.org/10.1007/s11104-017-3555-8

Malique F, Ke P, Boettcher J et al (2019) Plant and soil effects on denitrification potential in agricultural soils. Plant Soil 439:459-474. https://doi.org/10.1007/s11104-019-04038-5

Maruyama H, Sasaki T, Yamamoto Y, Wasaki J (2019) AtALMT3 is involved in malate efflux induced by phosphorus deficiency in Arabidopsis thaliana root hairs. Plant Cell Physiol 60:107-115. https://doi.org/10.1093/pcp/pcy190

Maurer D, Kiese R, Kreuzwieser J, Rennenberg H (2018) Processes that determine the interplay of root exudation, methane emission and yield in rice agriculture. Plant Biol 20:951-955. https://doi.org/10.1111/plb.12880

Moreau D, Pivato B, Bru D et al (2015) Plant traits related to nitrogen uptake influence plantmicrobe competition. Ecology 96:2300-2310. https://doi.org/10.1890/14-1761.1

Morley NJ, Richardson DJ, Baggs EM (2014) Substrate induced denitrification over or under estimates shifts in soil N2/N2O ratios. PLoS One 9:1-6. https://doi.org/10.1371/journal. pone. 0108144

Neumann G, Römheld V (2007) The release of root exudates as affected by the plant physiological status. In: Pinton R, Varanini Z, Nannipieri Z (eds) The rhizosphere: biochemistry and organic substances at the soil-plant interface, 2nd edn. CRC Press, pp 23-72

Neumann G, Bott S, Ohler MA et al (2014) Root exudation and root development of lettuce (lactuca sativa 1. Cv. Tizian) as affected by different soils. Front Microbiol 5:2. https://doi. org/10.3389/fmicb.2014.00002

Nguyen C (2003) Rhizodeposition of organic C by plants: mechanisms and controls. Agronomie 23:375-396. https://doi. org/10.1051/agro:2003011

O’Sullivan CA, Fillery IRP, Roper MM, Richards RA (2016) Identification of several wheat landraces with biological nitrification inhibition capacity. Plant Soil 404:61-74. https://doi.org/10.1007/s11104-016-2822-4

Oburger E, Jones DL (2018) Sampling root exudates - Mission impossible? Rhizosphere 6:116-133. https://doi.org/10. 1016/j.rhisph.2018.06.004

Philippot L, Čuhel J, Saby NPA et al (2009) Mapping field-scale spatial patterns of size and activity of the denitrifier community. Environ Microbiol 11:1518-1526. https://doi.org/ 10.1111/j.1462-2920.2009.01879.x

Preece C, Farré-Armengol G, Llusià J, Peñuelas J (2018) Thirsty tree roots exude more carbon. Tree Physiol 38:690-695. https://doi.org/10.1093/treephys/tpx163

Richardson AE, Simpson RJ (2011) Soil microorganisms mediating phosphorus availability. Plant Physiol 156:989-996. https://doi.org/10.1104/pp.111.175448

Rigby H, Clarke BO, Pritchard DL et al (2016) A critical review of nitrogen mineralization in biosolids-amended soil, the associated fertilizer value for crop production and potential for emissions to the environment. Sci Total Environ 541:1310-1338. https://doi.org/10.1016/j.scitotenv.2015.08. 089

Sasse J, Martinoia E, Northen T (2018) Feed your friends: Do plant exudates shape the root microbiome? Trends Plant Sci 23:25-41. https://doi.org/10.1016/j.tplants.2017.09.003

Schimel JP, Bennett J (2004) Nitrogen mineralization: challenges of a changing paradigm. Ecology 85:591-602. https://doi. org/10.1890/03-8002 
Smith MS, Tiedje JM (1979) The effect of roots on soil denitrification1. Soil Sci Soc Am J 43:951. https://doi.org/10.2136/ sssaj1979.03615995004300050027x

Valentinuzzi F, Cesco S, Tomasi N, Mimmo T (2015) Influence of different trap solutions on the determination of root exudates in Lupinus albus L. Biol Fertil Soils 51:757-765. https://doi.org/10.1007/s00374-015-1015-2

Vives-Peris V, de Ollas C, Gómez-Cadenas A, Pérez-Clemente RM (2019) Root exudates: from plant to rhizosphere and beyond. Plant Cell Rep. https://doi.org/10.1007/ s00299-019-02447-5
Vranova V, Rejsek K, Skene KR et al (2013) Methods of collection of plant root exudates in relation to plant metabolism and purpose: a review. J Plant Nutr Soil Sci 176:175-199. https://doi.org/10.1002/jpln.201000360

Publisher's note Springer Nature remains neutral with regard to jurisdictional claims in published maps and institutional affiliations. 